\title{
Materials and Orthopedic Applications for Bioresorbable Inductively Coupled Resonance Sensors
}

\author{
Aleksi Palmroth,* Timo Salpavaara, Petri Vuoristo, Sanna Karjalainen, Tommi Kääriäinen, \\ Susanna Miettinen, Jonathan Massera, Jukka Lekkala, and Minna Kellomäki
}

Cite This: ACS Appl. Mater. Interfaces 2020, 12, 31148-31161

Read Online

\section{ACCESS | Lلll Metrics \& More | 回 Article Recommendations | S1 Supporting Information}

ABSTRACT: Bioresorbable passive resonance sensors based on inductor-capacitor (LC) circuits provide an auspicious sensing technology for temporary battery-free implant applications due to their simplicity, wireless readout, and the ability to be eventually metabolized by the body. In this study, the fabrication and performance of various LC circuit-based sensors are investigated to provide a comprehensive view on different material options and fabrication methods. The study is divided into sections that address different sensor constituents, including bioresorbable polymer and bioactive glass substrates, dissolvable metallic conductors, and atomic layer deposited (ALD) water barrier films on polymeric substrates. The manufactured devices included a polymer-based pressure sensor that remained pressure responsive for 10 days in aqueous conditions, the first wirelessly readable bioactive glass-based resonance sensor for monitoring

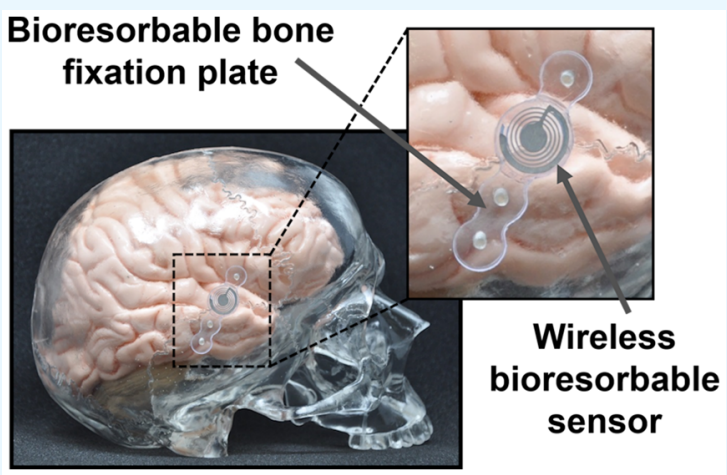
the complex permittivity of its surroundings, and a solenoidal coil-based compression sensor built onto a polymeric bone fixation screw. The findings together with the envisioned orthopedic applications provide a reference point for future studies related to bioresorbable passive resonance sensors.

KEYWORDS: transient electronics, biodegradable sensor, bioresorbable, resonance sensor, wireless, orthopedics

\section{INTRODUCTION}

Implantable sensors have been used for research purposes as part of orthopedic fixation devices for decades, but their clinical usage has remained scarce. The early smart implant systems utilized percutaneous wires for power and data transfer, but the wires are known to increase infection risks and may constrain the device usage to hospital surroundings. ${ }^{1-3}$ One approach for wireless sensor systems involves inductively coupled passive resonance sensors, which essentially consist of a parallel circuit of an inductor (L) coil and a capacitor (C). Such sensors operate without batteries, which reduces their size and complexity, thus making them easier to integrate into orthopedic implants. ${ }^{4}$ As a recent approach, sensors made from bioresorbable materials are designed to operate for a defined time under physiological conditions, after which they degrade into nontoxic substances that can be eliminated from the body. ${ }^{5,6}$

The operational principle of the sensors is based on inductive coupling between the LC circuit and a reader coil, whereupon a resonance curve is created at a given frequency range. The resonance curve may form a peak or a dip, depending on whether the real part of the impedance or the phase of the impedance is measured, respectively. Typically, the capacitance or inductance of the sensor changes in response to a measured variable, which shifts the resonance curve. This can be detected by estimating the frequency of the maximum or minimum value of the curve (depending on whether the resonance curve is a peak or a dip, respectively). A review by Huang et al. discusses the operational principle and state-of-the-art of these sensors in more detail.

A typical resonance sensor consists of a planar or solenoidal inductor coil connected to an interdigital or parallel-plate capacitor, which is often used as the sensing element. In addition, the sensors comprise a certain resistance $(\mathrm{R})$ and may contain separate resistive components, which is why the term RLC circuit is sometimes used. Passive resonance sensors enable a variety of measurement applications, including but not limited to pressure, strain, $\mathrm{pH}$, temperature, and biochemical sensing. ${ }^{7}$

Bioresorbable sensors are, by definition, only suitable for short-term applications. For example, after an open reduction and internal fixation (ORIF) of broken bones, the sensors could be added into the fixation devices to temporarily

Received: April 20, 2020

Accepted: June 22, 2020

Published: June 22, 2020 
a

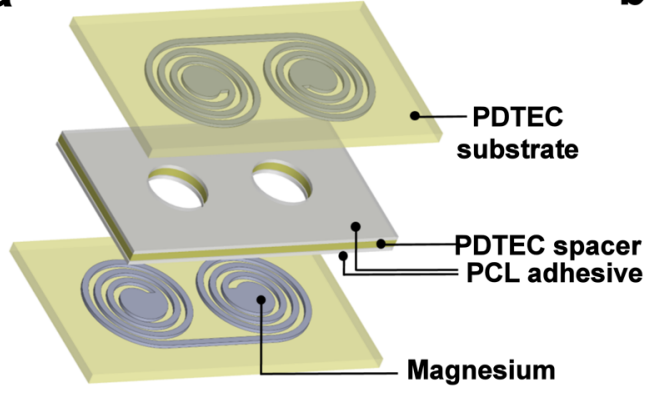

b

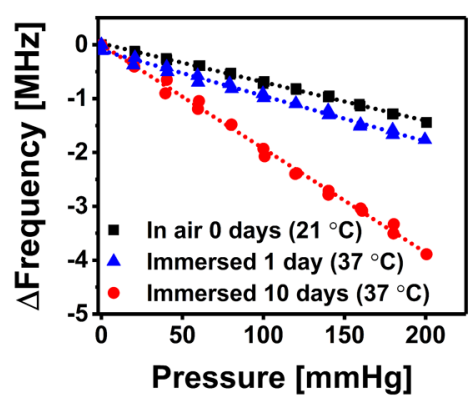

C

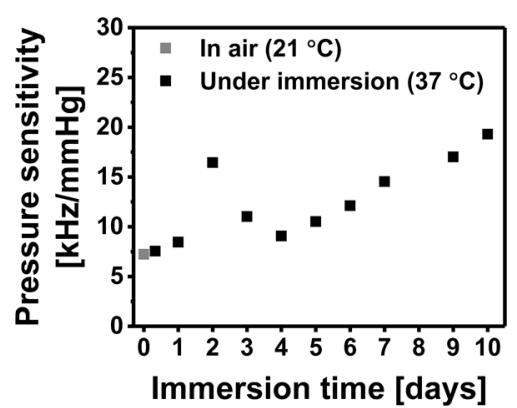

d

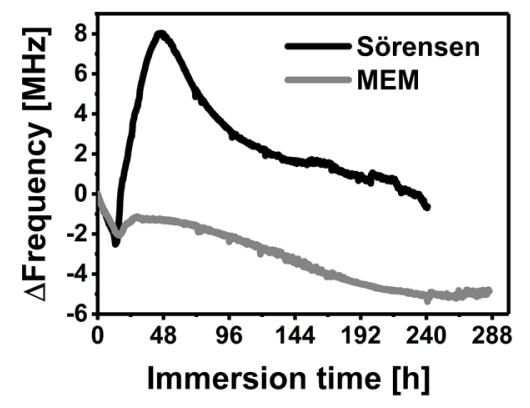

g

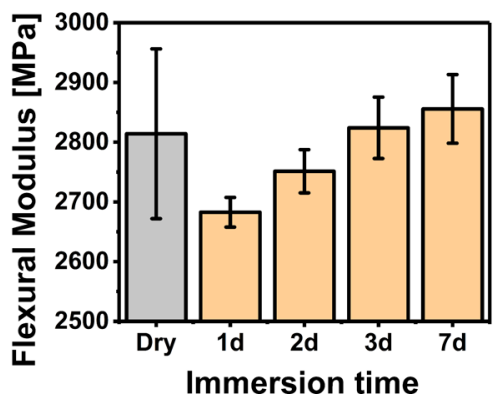

e

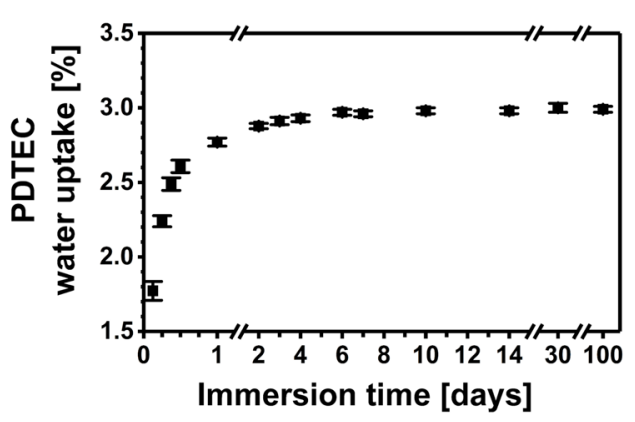

f

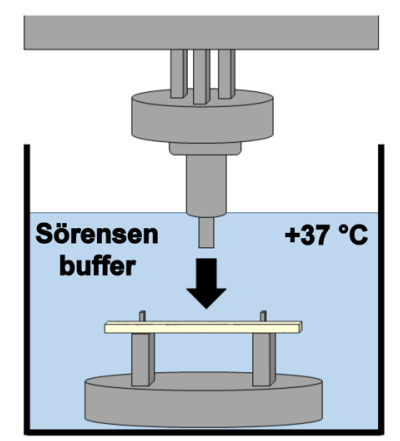

h

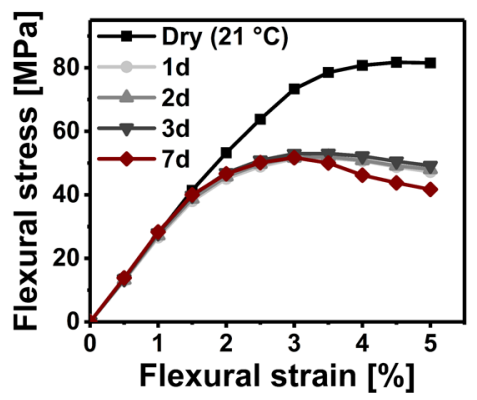

i

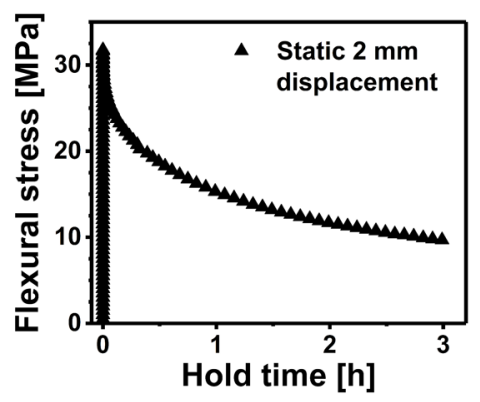

Figure 1. (a) Architecture of the wireless bioresorbable $\mathrm{Mg}$ pressure sensors, whose initial resonance frequencies in air are presented later in Table 1. (b) Examples of the pressure response of the sensor in air before immersion and in Sörensen buffer solution after 1 and 10 days of immersion. (c) Measured pressure sensitivities of the sensor immersed in Sörensen buffer. (d) Drifting of the pressure sensor resonance frequency under immersion without applied pressure. (e) Water uptake properties of PDTEC. (f) Measurement setup for all the mechanical tests, where the threepoint bending of the PDTEC samples was performed under immersion at $+37^{\circ} \mathrm{C}$. (g) Flexural moduli of the immersed PDTEC samples. The initial, day 0 dry value was measured at $+21^{\circ} \mathrm{C}$. (h) Flexural stress-strain curves of PDTEC as tested under immersion at various time points. (i) Stress relaxation behavior of PDTEC in aqueous conditions under a static $2 \mathrm{~mm}$ displacement.

monitor parameters like temperature for early signs of infection, intratissue pressure for cues of acute compartment syndrome, or strain to measure the stiffness of the fracture callus or to personalize tendon rehabilitation processes. ${ }^{4,8-10}$ Furthermore, intraoperative load sensors have provided improved results in total knee replacements by guiding the surgeon toward correct knee loading. ${ }^{11}$ Similar sensor-guided operations could be performed with smart implants where a bioresorbable sensor would be integrated into the orthopedic implant. These kinds of applications could reduce unnecessary patient discomfort and facilitate massive savings by detecting adverse events early or by reducing revision surgeries and expensive imaging procedures. 4 , 12

One of the main challenges in bioresorbable sensors is their fabrication. In many cases, the bioresorbable substrates are incompatible with conventional microfabrication processes like electrodeposition, photolithography, and etching. ${ }^{13,14}$ The process steps may involve spin-coating materials with organic solvents, baking at high temperatures, or immersing the substrates into electrodeposition solutions or lift-off chemicals. The associated conditions may damage the substrates or already prepared functional layers, which complicates the assembly of bioresorbable sensors.

The aim of this study is to provide an overall materials perspective on bioresorbable passive resonance sensors by discussing different material options, fabrication methods, and sensor architectures. The experimental novelty of the work lies in two original sensors, new material combinations and discussion of in vitro testing methods. Furthermore, an improved version of a previously published pressure sensor is utilized to discuss the effect of polymer substrates on the sensor performance as well as to compare physical vapor deposited (PVD) magnesium $(\mathrm{Mg})$ and zinc $(\mathrm{Zn})$ conductors. The novel sensor architectures include the first bioactive glassbased wireless resonance sensor and a molybdenum (Mo) wire-based compression sensor with a solenoidal design. The 
performance of the devices is demonstrated with wireless sensor measurements, on top of which the material properties of the components are evaluated in simulated physiological conditions. Finally, the water barrier materials are addressed by evaluating atomic layer deposited (ALD) encapsulation films, which are deposited on bioresorbable polymer substrates. In addition to the experimental results, several potential orthopedic applications are suggested for wireless bioresorbable sensors.

\section{RESULTS AND DISCUSSION}

2.1. Bioresorbable Polymer-Based Pressure Sensors. Bioresorbable wireless pressure sensors reported so far are mostly based on polymeric substrates. ${ }^{3,15-18}$ This is rational because bioresorbable polymeric bone fixation plates have been used for decades especially in pediatric patients, where permanent fixation might hinder bone growth. ${ }^{19}$ Thus, fabricating the sensors directly onto the orthopedic plates offers one simple possibility for integrating the sensors onto the implants. In this study, the material attributes of a recently reported polymer-based bioresorbable pressure sensor ${ }^{18}$ were adjusted regarding the adhesive layers and $\mathrm{Mg}$ conductor patterns. This section involves testing these $\mathrm{Mg}$ pressure sensors and characterizing the water uptake and flexural properties of the substrate material in simulated physiological conditions.

The $\mathrm{Mg}$ pressure sensors were fabricated by attaching two poly(desaminotyrosyl-tyrosine ethyl ester carbonate) (PDTEC) substrates $(430 \mu \mathrm{m})$ with e-beam evaporated $\mathrm{Mg}$ conductor patterns $(7.5 \mu \mathrm{m})$ onto a holed spacer by using molten polycaprolactone (PCL) films $(\sim 15 \mu \mathrm{m})$ as an adhesive (Figure 1a). The working principle of the sensor is based on variable capacitors formed by the $\mathrm{Mg}$ electrodes on the substrates; as pressure is increased, the electrodes bend toward each other in the two cavities that are confined by the substrates and the holes in the spacer. This increases the capacitance of the LC circuit, which is detected as a shifting resonance peak (or decreased resonance frequency) as illustrated earlier. ${ }^{18}$ In this study, the adhesive PCL layer that attaches the substrates into the spacer was about twice as thick than in the previous version. This was assumed to increase the functional lifetime of the pressure sensor because in the anterior publication the substrates were noticed to detach from the spacer during immersion. In addition, the evaporation masks were now fabricated from laser-cut metal sheets instead of $3 \mathrm{D}$-printed polymers that were used in the earlier study. ${ }^{18}$ The masks were redesigned to remove excessive $\mathrm{Mg}$ from around the coils to reduce possible stray capacitances.

In this study, the sensor remained readable and responded to pressure changes under immersion in the Sörensen buffer solution for 10 days, after which the resonance peak $(\sim 101$ $\mathrm{MHz}$ ) was largely attenuated and the test was terminated. The Sörensen buffer was chosen to reliably compare the sensor behavior with our previously reported pressure sensor, which had failed during the first $24 \mathrm{~h}$ of immersion. ${ }^{18}$ In addition, a similar sensor was now immersed in Minimum Essential Medium (MEM) to more accurately simulate the contents of physiological solutions. ${ }^{20}$ The sensor was readable in MEM for up to 12 days. Thereafter, the detection of the resonance frequency $(\sim 88 \mathrm{MHz})$ was not reliable anymore due to resonance peak attenuation, which increased the uncertainty in estimating the resonance frequency. The attenuation was caused by the corroding $\mathrm{Mg}$ conductors, which increased the electrical resistance in the circuit. Furthermore, the increasing resistance may decrease the resonance frequency. ${ }^{21}$ The effects of the resistance on the resonance frequency are often neglected in conventional applications where the resistances are diminutive, but should be taken into account in biodegradable devices where the resistances and their changes can be more significant.

Bacterial growth was noticed as a film on top of the MEM solution upon test termination after 14 days, which may potentially have accelerated $\mathrm{Mg}$ corrosion via acidification. ${ }^{22}$ As discussed later in section 2.3, the differences in the simulated physiological conditions have a significant impact on the metal corrosion. On the other hand, the contamination risks and increased complexity of the test setups advocate for using simpler buffer solutions than cell culture media in sensor measurements, where the conductors are encapsulated. This is because the encapsulation layers diminish the effect of proteins and other nonpermeable substances on the metal corrosion.

The initial resonance frequencies of the immersed sensors in Sörensen and MEM were $101.89 \mathrm{MHz}(106.57 \mathrm{MHz}$ in air) and $92.76 \mathrm{MHz}(98.67 \mathrm{MHz}$ in air), respectively. The resonance frequencies decreased during the first $12 \mathrm{~h}$ (Figure 1d), caused by the capacitance increase due to water diffusion into the PDTEC substrates. Thereafter, the resonance frequency of the sensor started to rise, which is earlier shown to result from the outward bending of the substrates. ${ }^{18}$ This could have been caused by relaxation or swelling of the substrates or possibly by hydrogen gas generation arising from the corrosion of $\mathrm{Mg}^{20}$ Furthermore, the corrosion increased the resistance of the conductors, which can be considered as one of the factors that contribute to the drifting. The small amount of water that diffused into the polymer matrix could have slowly initiated the dissolution of $\mathrm{Mg}$, possibly explaining why no clear corrosion was noticed after $24 \mathrm{~h}$ of immersion. ${ }^{18}$ The materials testing revealed that the water uptake of PDTEC was $2.5 \mathrm{wt} \%$ after $12 \mathrm{~h}$, in contrast to the final equilibrium state of $3.0 \mathrm{wt} \%$ after a few days (Figure 1e). The water uptake remained at the same level during the rest of the 100 days test period, which is consistent with the reported slow degradation rate of PDTEC. ${ }^{23}$

The pressure response measurements (Figure $1 \mathrm{~b}$ ) showed that the initial sensitivity of the nonimmersed sensor was around $-7 \mathrm{kHz} / \mathrm{mmHg}$, which is in the same range compared to the previously reported set of sensors. ${ }^{18}$ The pressure sensitivity of the sensor was noticed to drift as a function of immersion time (Figure 1c). In comparison, the bioresorbable LC circuit-based pressure sensor of Luo et al. showed also slight sensitivity drifts under immersion, but the changes were much smaller. ${ }^{15}$ The three-point bending test showed only a modest increasing trend in the flexural Young's modulus of PDTEC during the first week, as tested under aqueous conditions at $37{ }^{\circ} \mathrm{C}$ (Figure 1f,g). Thus, the changes in the mechanical properties of PDTEC do not explain the nonlinear sensitivity drifting. Instead, the drifting was likely attributed to structural changes between the substrates and the adhesive PCL layers, possibly due to hydrogen generation inside the sensor. It can be concluded that the diffused water caused changes in the dielectric properties of the capacitors, dimensional changes in the substrate, and corrosion of the conductors, all of which are undesirable regarding sensor stability. The drifting of the sensor would require frequent calibration in practical implant applications. Thereby, we suggest that in this kind of sensor architecture the water 

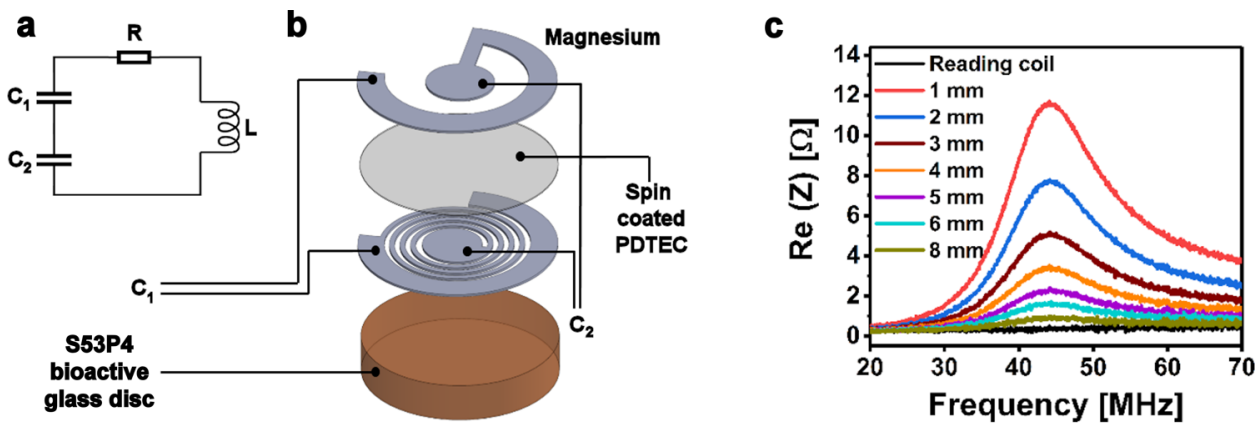

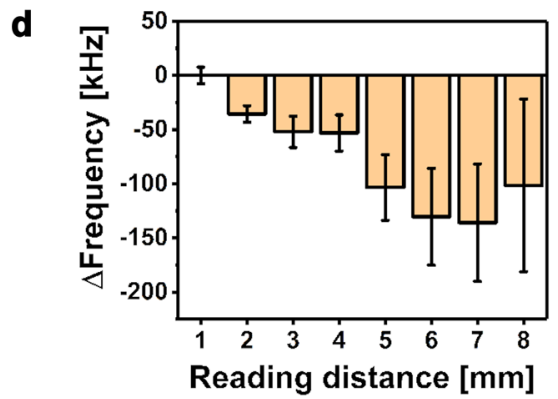

f

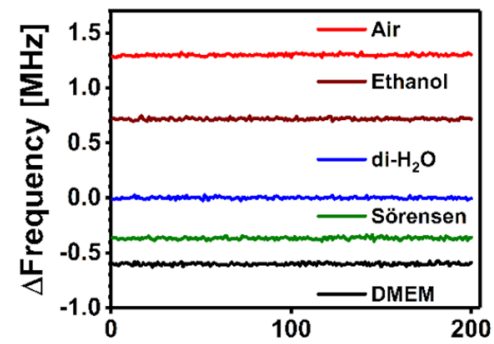

Amount of measurements

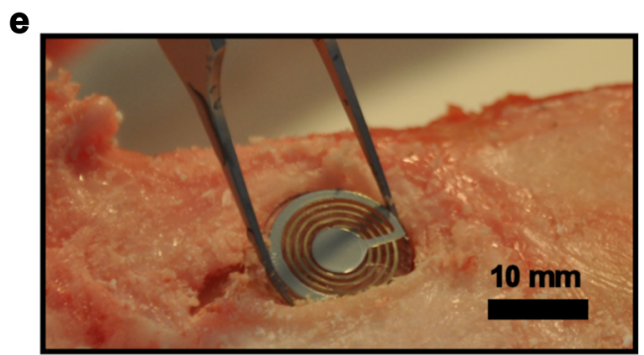

g

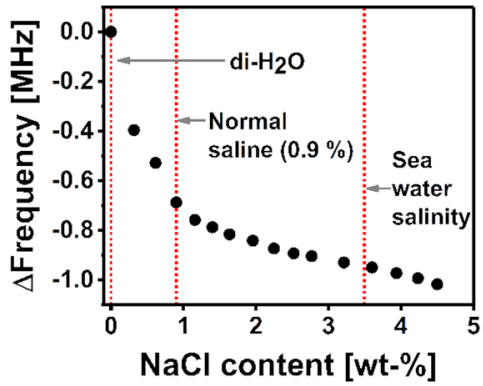

Figure 2. (a) A simplified lumped element model and (b) schematic structure of the bioactive glass-based resonance sensor. (c) Illustration of the resonance peaks at varying reading distances. (d) Effect of reading distance onto the resonance frequency $(\sim 44 \mathrm{MHz})$. The results are presented relative to the reading distance of $1 \mathrm{~mm}$ and given as mean \pm standard deviation $(n=100)$. (e) An envisioned application of the sensor as a sensorcontaining bone graft disc shown in a cadaveric porcine tibia. (f) Relative resonance frequency behavior of a parylene-coated sensor embedded in different media, where the mean of 200 measurements in deionized water $\left(\mathrm{di}_{-} \mathrm{H}_{2} \mathrm{O}\right)$ has been set as the zero point. $(\mathrm{g}) \mathrm{Effect}$ of increasing $\mathrm{NaCl}$ content in the resonance frequency of the coated sensor embedded in di- $\mathrm{H}_{2} \mathrm{O}$.

diffusion into the polymer matrix should be ideally fully prevented during the functional lifetime of the sensor, regardless of the degradation rate of the conductor material. This could be achieved for example with an appropriate bioresorbable encapsulation layer.

The PDTEC samples tested in dry conditions exhibited increased flexural strength compared to the wet samples (Figure 1h). While dry samples maintained the same stress values beyond the yield point, the immersed samples showed strain softening. The stress needed to flex the PDTEC samples to a constant displacement of $2 \mathrm{~mm}$ under aqueous conditions decreased significantly within $3 \mathrm{~h}$ of testing (Figure 1i). The stress relaxation behavior could be of significance in applications where the pressure is static. In addition to the mechanical properties, the response of human fibroblasts to compression-molded PDTEC discs was evaluated (Figure S1, Supporting Information), indicating that their biocompatibility was at least comparable to, if not better than, that of poly-L/Dlactide 96L/4D (PLDLA 96/4) discs or untreated polystyrene well plates.

Possible applications for bioresorbable pressure sensors include detecting adverse conditions during or after the surgery. For example, craniosynostosis is a malformation of an infant's skull caused by premature ossification of cranial sutures, which is often treated with a cranial vault remodeling by using bioresorbable plates and screws. Elevated intracranial pressure (ICP) levels after surgery may potentially require further treatment, which is why wireless postoperative ICP monitoring would be desirable. ${ }^{24}$ Detecting acute compartment syndrome (ACS), which is caused by elevated pressure inside muscle compartments, is another attractive application for temporary pressure sensors. The diagnosis usually relies in clinical symptoms such as disproportionately severe pain and paresthesia, but delays between initial assessment and diagnosis are still frequent, leading to irreversible ischemic damage in $6-8 \mathrm{~h}$ if the condition is not properly treated. ${ }^{25}$ Implantable pressure sensors could be used to detect cues of ACS in unresponsive or sedated patients or to complement clinical assessment in other risk groups. Finally, sensors could be used to guide surgeons during the operation. For example, pressure sensors could be used to avoid periosteal necrosis and subsequent osteopenia, which may arise from applying too much compression on a bone fixation plate. ${ }^{26}$ Embedding such sensors onto fixation plates could aid in the adoption of the 
technology, as there would be fewer modifications to the surgical techniques compared to external sensors that are removed in the end of the operation.

2.2. Bioactive Glass-Based Wireless Resonance Sensors. Bioresorbable glasses and ceramics offer underrepresented yet fascinating substrate materials for wireless resonance sensors. Invented by Larry Hench, bioactive glasses can create a strong bonding interface with bone or even with soft tissues by releasing soluble ions upon immersion in water. ${ }^{27}$ These ions stimulate osteogenic cells and contribute to the formation of a bonelike apatite layer onto the glass surface, due to which such glasses are clinically used for example as synthetic bone grafts. The dissolution kinetics of bioactive glasses can be adjusted by their composition, and certain glass compositions are fully bioresorbable. Even though fast dissolving borate glasses have been proposed as sensor substrates, the interest toward bioactive glasses in biodegradable electronics has been scarce. ${ }^{28,29}$ Herein, we present the first wirelessly measured bioactive glass-based resonance sensor with S53P4 (Bonalive) glass disc substrates, dissolvable $\mathrm{Mg}$ conductors, and spin-coated bioresorbable polymer dielectric layer.

A simplified electrical design and the schematic structure of the bioactive glass-based resonance sensor are presented in Figure 2a,b. The sensor architecture consisted of spin-coated PDTEC dielectric layers $(\sim 1 \mu \mathrm{m})$ and $\mathrm{Mg}$ conductors (7.5 $\mu \mathrm{m})$ that were e-beam evaporated through $3 \mathrm{D}$-printed stencil masks. Figure $2 \mathrm{c}$ presents the measured graphs of the impedance spectrum with increasing reading distances. Because no batteries are needed in the sensors, the most critical limiting factor for their miniaturization is the size of the coil, which has a strong effect on the reading distance of the device. ${ }^{2,7}$ The bioactive glass-based sensor showed a detectable but attenuated resonance peak $(\sim 44 \mathrm{MHz})$ at a distance of 8 $\mathrm{mm}$, which is in line with the previously reported $14 \mathrm{~mm}$ reading distance for the $\mathrm{Mg}$ pressure sensors with larger coils. ${ }^{18}$ For comparison, the reading distance for nondegradable intraocular resonance pressure sensors with a diameter of 6 $\mathrm{mm}$ have been reported at $30 \mathrm{~mm}$ already in 1967 by Collins. ${ }^{30}$ A more recent example with $4 \times 4 \mathrm{~mm}^{2}$ pressure sensors reached a $15 \mathrm{~mm}$ reading distance by using $\mathrm{Cu}$ conductors. ${ }^{31}$

The uncertainty in detecting the resonance frequency from the attenuated peaks increased along with the increasing reading distance (Figure $2 \mathrm{~d}$ ). In addition, the determined resonance frequency changed with the increasing reading distance due to parasitic capacitances between the sensor and the reader coil. ${ }^{32}$ This feature might require compensation in practical applications.

One potential application for passive resonance sensors is monitoring complex permittivity changes in their close proximity. ${ }^{3,34}$ This feature is attributed to the electrical field in the capacitor, which partly reaches the environment of the sensor. Changes in the permittivity of the immediate sensor environment affect its capacitance and thus shift the resonance frequency of the device. For example, nondegradable sensors with interdigital capacitors (finger electrodes) as sensing elements have been earlier tested for monitoring the degradation behavior of bioresorbable polymers as well as for distinguishing different tissues. ${ }^{35,36}$ The finger electrodes offer the possibility to confine most of the interactions between the electrical field and the sensor surroundings near these electrodes. $^{34}$
The fabricated bioactive glass-based resonance sensors were used to demonstrate the complex permittivity sensing capability by distinguishing different media in which the sensor was embedded (Figure 2f). The sensors were first coated with nondegradable parylene $(13 \mu \mathrm{m})$ to eliminate the effect of $\mathrm{Mg}$ corrosion during the tests. The standard deviations of the estimated resonance frequencies $(n=200)$ in air, ethanol, and di- $\mathrm{H}_{2} \mathrm{O}$ were $9.7,9.5$, and $9.4 \mathrm{kHz}$, respectively. Correspondingly, those of Sörensen buffer and Dulbecco's Modified Eagle Medium (DMEM) with high glucose were 10.8 and $10.7 \mathrm{kHz}$. The $\sim 15 \%$ higher standard deviations in Sörensen or DMEM solutions compared to di$\mathrm{H}_{2} \mathrm{O}$ can be explained by their ionic content. In another test, a nonlinear resonance frequency decrease was observed as saline was gradually added into $\mathrm{di}-\mathrm{H}_{2} \mathrm{O}$ where the sensor was immersed (Figure $2 \mathrm{~g}$ ). The result was caused by the capacitance increase originating from the addition of sodium and chloride ions.

A highly desirable potential application (Figure 2e) for resonance sensors made from bioactive glass would be monitoring the formation of the apatite layer and the subsequent bonding of bone onto the glass. The sensors could be integrated onto bioactive glass plates that have been clinically used for repairing orbital floor fractures and nasal septal perforations. ${ }^{37}$ A similar sensing method could be of benefit also in nondegradable implants like total hip prostheses. This kind of quick osseointegration measurement could complement or even replace conventional imaging procedures and aid in personalizing rehabilitation.

To conclude, glass substrates contain several advantages over polymeric alternatives, such as better compatibility with conventional microfabrication processes. $^{29}$ For example, bioactive glasses tolerate solvents like acetone and elevated temperatures that may be required for lithography processes utilizing photoresist masks. A recent study demonstrated dry fabrication methods for $\mathrm{Mg}$ microcoils and heaters on float glass substrates, requiring only four steps: $\mathrm{Mg}$ deposition, photolithography for pattern definition, ion beam etching of $\mathrm{Mg}$, and resist stripping with oxygen plasma and acetone. ${ }^{38}$ This is one example of methods that could be useful with bioactive glass substrates for fabricating devices with detailed conductor patterns.

2.3. Fabrication and Properties of Bioresorbable Conductor Metals. The prevalent bioresorbable conductor materials are metals such as $\mathrm{Mg}, \mathrm{Zn}, \mathrm{Mo}$, iron $(\mathrm{Fe})$, and tungsten $(\mathrm{W})$, out of which all but $\mathrm{W}$ are dietary minerals. Yin et al. have reported the electrical and corrosion properties of various dissolvable metal thin films $(40-300 \mathrm{~nm})$ because their properties might be very different compared to bulk materials. ${ }^{39}$ Nevertheless, more studies are needed to cover the relevant behavior of bioresorbable metal films, especially in radio-frequency (RF) applications where the films are typically measured in micrometers rather than nanometers and their electrical properties may be affected by the skin effect. In this section, the fabrication, structure, electrical properties, and corrosion behavior of a few micrometers thick $\mathrm{Mg}$ and $\mathrm{Zn}$ thin films are discussed, including the drastic effect of different corrosion test conditions. In addition, alternative fabrication methods for bioresorbable conductors are briefly summarized.

In LC circuits, lower electrical resistance of the inductor coil generally enables higher quality resonators with longer reading distances. ${ }^{2}$ However, at high frequencies, the skin effect may restrict the current flow on the surface of the conductors. ${ }^{40}$ For 


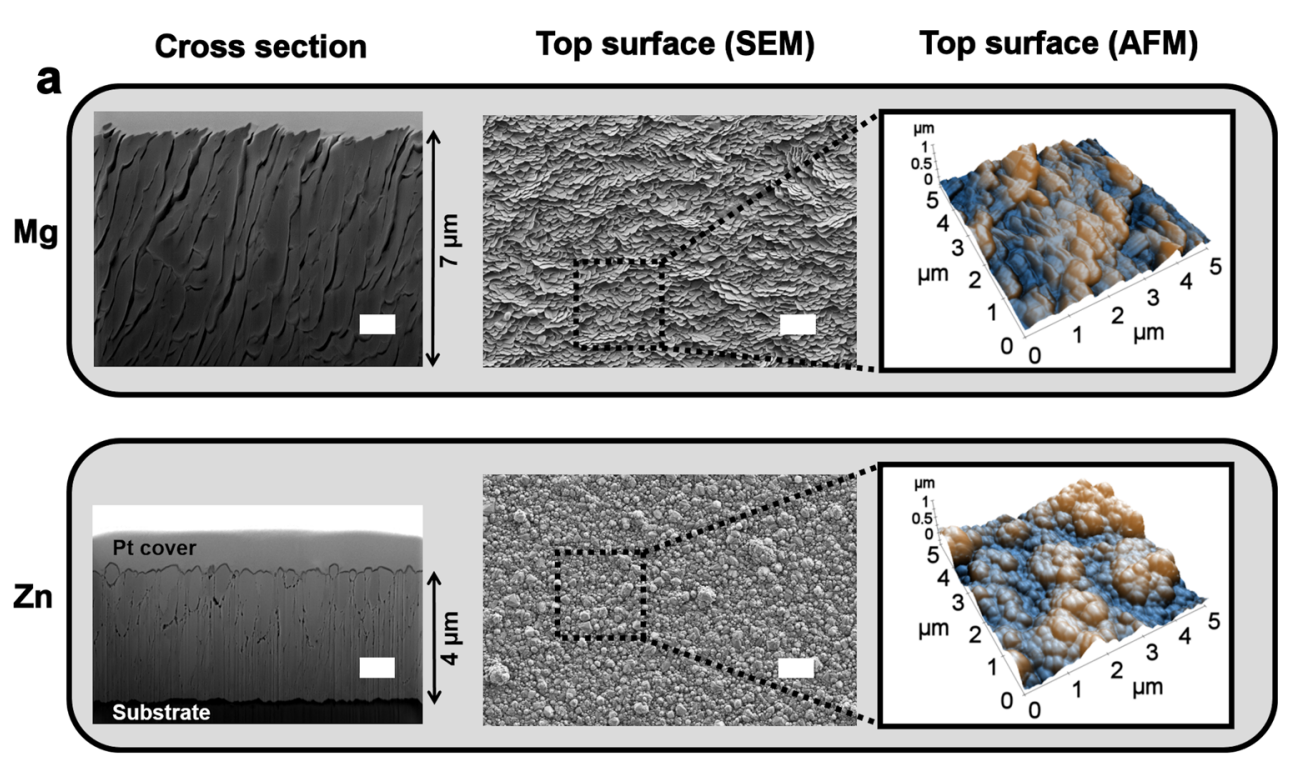

b

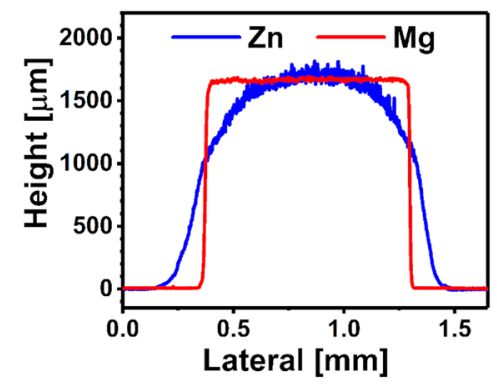

C

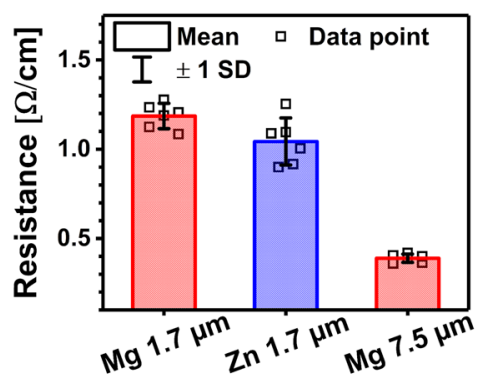

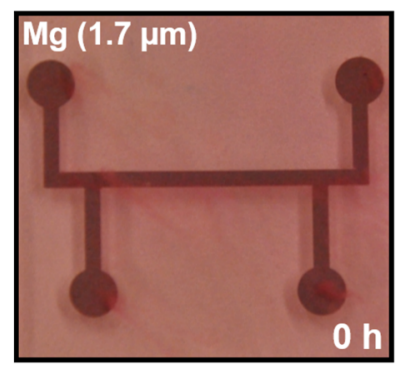
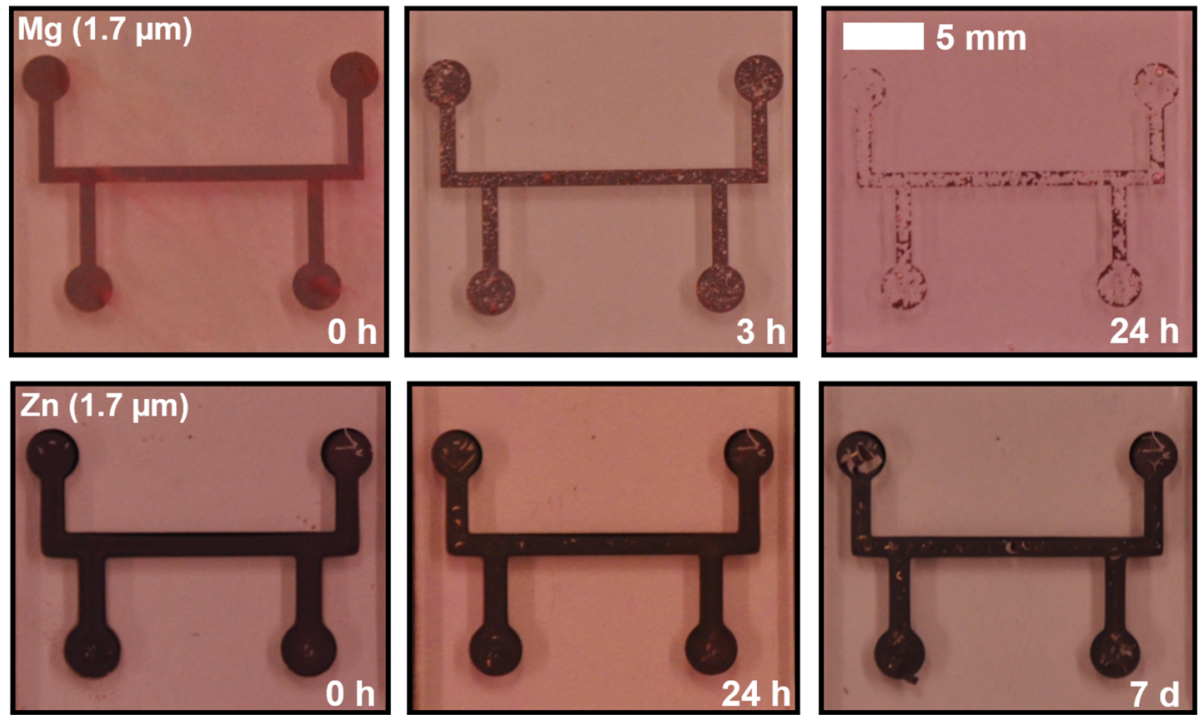

Figure 3. (a) Structure of the evaporated $\mathrm{Mg}(7.5 \mu \mathrm{m})$ and sputtered $\mathrm{Zn}$ films $(\sim 4 \mu \mathrm{m})$ illustrated by FIB-SEM, FE-SEM, and AFM techniques. White scale bars $1 \mu \mathrm{m}$. (b) Cross-sectional profiles of the $1.7 \mu \mathrm{m}$ thick $\mathrm{Mg}$ and $\mathrm{Zn}$ films. (c) Electrical resistances of the $\sim 1 \mathrm{~mm}$ wide $\mathrm{Mg}$ and $\mathrm{Zn}$ films given as mean \pm standard deviation $(n=6)$. (d) Photographs of the metal films in cell culture medium at $+37{ }^{\circ} \mathrm{C}$ in $5 \% \mathrm{CO}_{2}$.

instance, pure Fe has been considered as a poor conductor choice for LC resonators due to its low skin depth. ${ }^{15,41}$ Table S1 summarizes the skin depths of $\mathrm{Mg}, \mathrm{Zn}, \mathrm{Fe}$, and $\mathrm{Mo}$ at different frequencies. The recommended maximum conductor thickness in RF applications is about 3-5 times the skin depth because conductors much thicker than this do not result in significant increases in the $Q$-factor. ${ }^{42}$
Physical vapor deposition (PVD) methods are attractive for fabricating conductors because they can be utilized without transfer printing, and the techniques can be readily applied onto many types of substrates. In this study, e-beam evaporation was used for $\mathrm{Mg}$ deposition, as it is known to be a capable method for producing $\mathrm{Mg}$ films at the micrometer scale. $^{43-45}$ On the contrary, the $\mathrm{Zn}$ films were magnetron sputtered because the high vapor pressure of $\mathrm{Zn}$ results easily 
in undesirable wall deposits in evaporation systems. ${ }^{46}$ Evaporated $\mathrm{Mg}(7.5 \mu \mathrm{m})$ and sputtered $\mathrm{Zn}(\sim 4 \mu \mathrm{m})$ films were first deposited on bioresorbable PDTEC substrates to study the morphology of the conductors. A prolonged $\mathrm{Zn}$ sputtering process was noticed to heat the PDTEC substrates over their glass transition temperature $\left(T_{\mathrm{g}}=99{ }^{\circ} \mathrm{C}\right)$, which impaired obtaining thicker $\mathrm{Zn}$ films. In addition, both metals $(1.7 \mu \mathrm{m})$ were deposited on glass substrates to compare their electrical characteristics and corrosion rates with minimal influence of the substrate.

The $\mathrm{Mg}$ film surface morphology (Figure 3a) consisted of similar facets as described recently with sputtered $\mathrm{Mg} .{ }^{47}$ The $\mathrm{Zn}$ film surfaces comprised individual grains together with larger clusters. The cross-sectional focused ion-beam SEM (FIB-SEM) images revealed that the $\mathrm{Mg}$ films had a coarse columnar structure compared to the denser structure of $\mathrm{Zn}$. The structure could explain why the $\mathrm{Zn}$ films $(1.7 \mu \mathrm{m})$ showed comparable or even slightly lower electrical resistances compared to $\mathrm{Mg}$ films of same thickness (Figure 3c). Comparing the approximated mean bulk resistivity of the 1.7 $\mu \mathrm{m}$ thick sputtered $\mathrm{Zn}$ films $(180 \mathrm{n} \Omega \cdot \mathrm{m})$ with that of the evaporated $\mathrm{Mg}$ films $(200 \mathrm{n} \Omega \cdot \mathrm{m})$ of similar thickness demonstrates that the fabrication method dominated the electrical properties of the films over intrinsic material properties. This can be concluded by comparing literature bulk resistivity values, which suggest that $\mathrm{Zn}(59 \mathrm{n} \Omega \cdot \mathrm{m})$ should be less conductive than $\mathrm{Mg}(44 \mathrm{n} \Omega \cdot \mathrm{m})$. The results illustrate the differences between thin films and bulk materials, which should be taken into account when choosing the conductor materials and their fabrication method.

The sharper profile of the $\mathrm{Mg}$ conductors (Figure $3 \mathrm{~b}$ ) originated from the directional nature of evaporation, where the material was deposited in a line of sight manner in contrast to more nondirectional sputtering, which resulted in an arched Zn film contour. ${ }^{48}$ The sputtering masks should thus be in a close contact with the substrate, as a short circuit might otherwise form between the coil turns. The disadvantages of fabricating the conductor patterns by using PVD together with shadow masks are related to limited resolution and the required vacuum conditions. ${ }^{14}$ Higher precision can be achieved by using lithographic masks, but transfer printing from a provisional substrate is often needed because most bioresorbable polymers do not tolerate the associated chemicals and temperatures. ${ }^{49}$ Alternative fabrication techniques include approaches, where patterned metal films are formed by micromachining or wet etching of metal foils. ${ }^{3,50-53}$ The advantage of these top-down methods is the easiness in obtaining thicker films compared to PVD or most other bottom-up processes. On the other hand, several tens of micrometers thick $\mathrm{Mg}$ and $\mathrm{Zn}$ microstructures have been obtained by electroplating the conductor patterns onto a temporary substrate and subsequently transfer printing them onto bioresorbable substrates. ${ }^{15,54}$ Further approaches include conductive ink printing methods that do not require vacuum technology and would thus be beneficial for scaling the manufacturing processes. ${ }^{14,55}$ These methods are currently under development, but the nonconductive surface oxide layers on biodegradable metal particles make their development challenging.

Yin et al. concluded that thin films of $\mathrm{Mg}, \mathrm{Mg}$ alloy AZ31B, and $\mathrm{Zn}$ degrade significantly faster compared to $\mathrm{Fe}, \mathrm{Mo}$, or W. ${ }^{39}$ Figure $3 \mathrm{~d}$ elucidates the degradation rate differences of $\mathrm{Mg}$ and $\mathrm{Zn}$ films $(1.7 \mu \mathrm{m})$ in cell culture medium (MEM supplemented with $10 \%$ fetal bovine serum and $1 \%$ antibiotics) at $+37{ }^{\circ} \mathrm{C}$ with $5 \% \mathrm{CO}_{2}$ supply, which is the recommended practice for in vitro corrosion testing of magnesium, as stated by Gonzalez et al. in their position paper. ${ }^{20} \mathrm{Mg}$ started to visibly degrade immediately upon immersion with corrosion pits present after $3 \mathrm{~h}$, and most of the film dissolved within the first $24 \mathrm{~h}$. Testing of thicker $\mathrm{Mg}$ films $(7.5 \mu \mathrm{m})$ revealed the dramatic difference in the degradation behavior between different conditions (Figure S2), which should be recognized when studying unprotected bioresorbable metal films. For example, the $\mathrm{Mg}$ samples in di- $\mathrm{H}_{2} \mathrm{O}$ and Sörensen buffer did not show similar pitting corrosion as those immersed in cell medium. Furthermore, mere addition of $5 \% \mathrm{CO}_{2}$ accelerated the corrosion of the films in di- $\mathrm{H}_{2} \mathrm{O}$. The Sörensen buffer resulted in a significantly faster degradation compared to cell culture medium, possibly due to lack of proteins and differences in the buffering system.

The $\mathrm{Zn}$ film surface appeared black, which may be caused by the observed $\mathrm{Zn}$ nanoclusters on top of the films. ${ }^{56}$ The dissolution of the $\mathrm{Zn}$ films was much slower compared to $\mathrm{Mg}$, but $\mathrm{Zn}$ flakes detached from the film already during the first 24 h. The slower degradation rate could be a benefit in applications where a longer sensor lifetime is desired. The corrosion of bulk $\mathrm{Zn}$ and $\mathrm{Mg}$ in simulated body fluid (SBF, $\mathrm{pH}$ 7) has been estimated to occur at a pace of 50 and $220 \mu \mathrm{m}$ year ${ }^{-1}$, respectively. ${ }^{57}$ Correspondingly, the dissolution rate for sputtered $\mathrm{Zn}$ thin films $(300 \mathrm{~nm})$ has been estimated at $120-$ $170 \mathrm{~nm} \mathrm{day}{ }^{-1}\left(44-62 \mu \mathrm{m}\right.$ year $\left.{ }^{-1}\right)$ in di- $\mathrm{H}_{2} \mathrm{O}$, with an observation that the films lose their electrical conductivity 10 times faster than it takes for the thickness to decrease to zero. ${ }^{39}$ Thus, nonpassivated $\mathrm{Mg}$ and $\mathrm{Zn}$ thin films are not considered practical in bioresorbable electronics. Instead, slower dissolving Mo was suggested for applications where the electrodes are in direct contact with biological tissues.

2.4. Bioresorbable Conductor Metals in Passive Resonance Sensors. Most bioresorbable inductively coupled devices reported so far utilize $\mathrm{Mg}$ as the conductor material. $3,18,38,51,58$ On the contrary, the first fully biodegradable resonance pressure sensor presented by Luo et al. was based on $50 \mu \mathrm{m}$ thick electroplated $\mathrm{Zn}$ films on top of a 5-10 $\mu \mathrm{m}$ Fe layer. In this section, the performances of $\mathrm{Mg}$ - and $\mathrm{Zn}$ based pressure sensors are compared. The schematic structure of the sensors is presented in Figure $1 \mathrm{a}$ with $\mathrm{Mg}$ conductors. Furthermore, the properties of wirelessly readable compression sensors with thick Mo wire $(200 \mu \mathrm{m})$ conductors around polymeric screws are presented.

The results indicate that magnetron sputtered $\mathrm{Zn}(\sim 4 \mu \mathrm{m})$ was sufficient for producing wireless pressure sensors with similar, virtually linear pressure responses compared to sensors made from $7.5 \mu \mathrm{m}$ thick $\mathrm{Mg}$ (Table 1 ). However, a practical

Table 1. Characteristics of the Fabricated $\mathrm{Mg}$ and $\mathrm{Zn}$ Pressure Sensors, Whose Pressure Responses Are Illustrated in Figure 4

$\begin{array}{ccc}\text { sample } & \begin{array}{c}\text { initial resonance frequency } \\ (\mathrm{MHz})\end{array} & \begin{array}{c}\text { pressure sensitivity } \\ \left(\mathrm{kHz} \mathrm{mmHg} \mathrm{mg}^{-1}\right)\end{array} \\ \mathrm{Mg} \text { sensor 1 } & 106.57 & -7.2 \\ \mathrm{Mg} \text { sensor 2 } & 99.57 & -6.7 \\ \mathrm{Mg} \text { sensor 3 } & 98.67 & -5.4 \\ \text { Zn sensor 1 } & 84.58 & -5.1 \\ \text { Zn sensor 2 } & 95.79 & -7.2 \\ \text { Zn sensor 3 } & 88.32 & -9.4\end{array}$



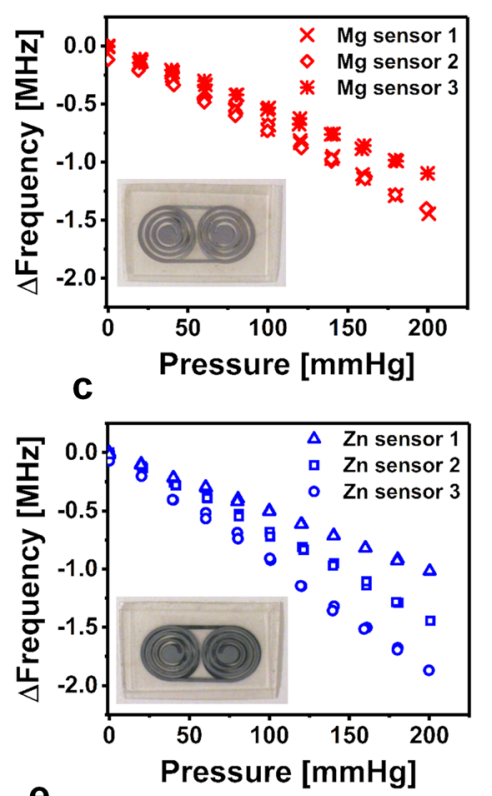

$\mathbf{e}$

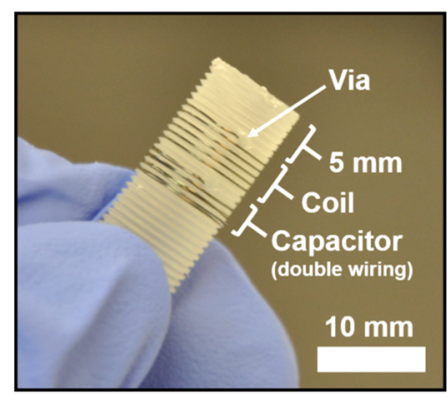

b
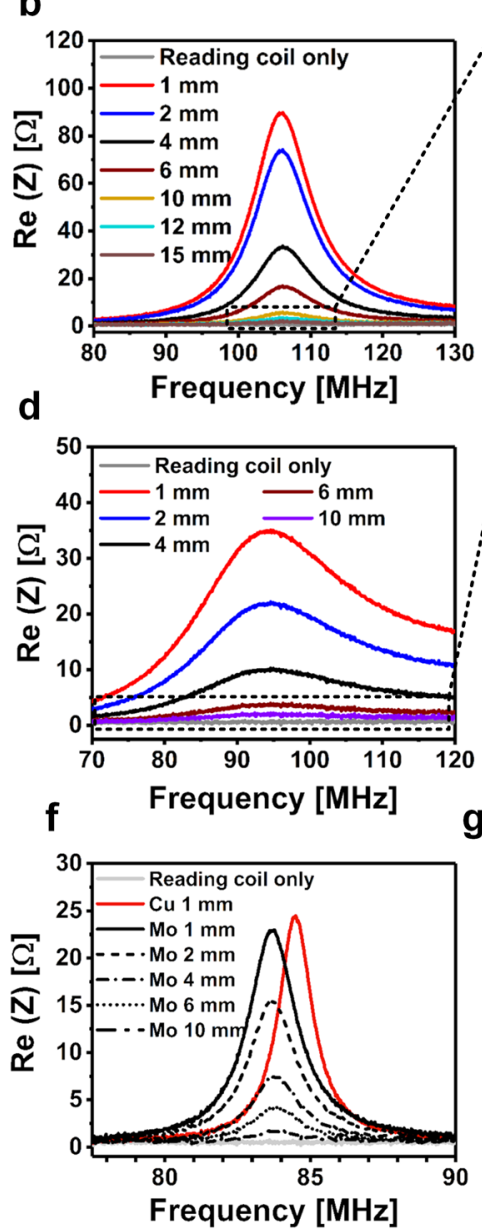
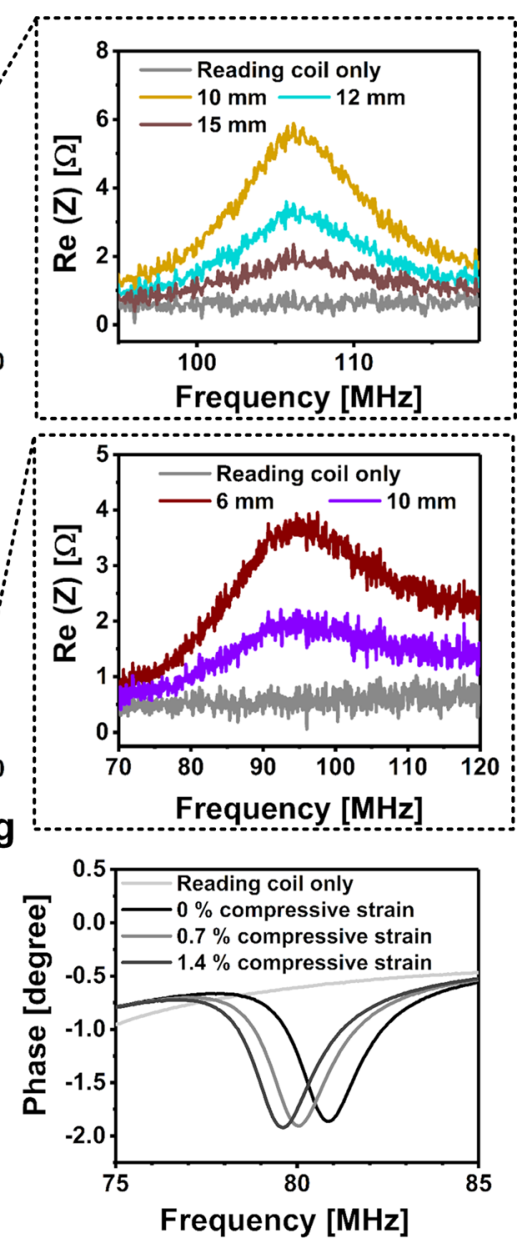

Figure 4. (a) Pressure responses of the bioresorbable $\mathrm{Mg}$ pressure sensors, as measured through a glass bottle from a reading distance of $6 \mathrm{~mm}$. A photograph of the sensor is shown in the inset. (b) Graphs of the impedance spectrum measured by increasing the reading distance of the Mg sensor, including rescaled graphs of the largest reading distances (on the right). The testing was performed by stacking $1 \mathrm{~mm}$ thick microscopy slides one by one between the sensor and the reader coil to stepwise increase the reading distance. (c, d) Corresponding $\mathrm{Zn}$ pressure sensor data. (e) Structure of the Mo wire compression sensor with a solenoidal coil. (f) Impedance spectrum graphs of the Mo compression resonance sensor with an increasing reading distance, including a reference measurement using a similar sensor made from $\mathrm{Cu}$ wire. In our measurement setup, the tip of the polymer screw adds another $5 \mathrm{~mm}$ to the indicated distance between the sensor coil and the reading coil. (g) Impedance phase graphs at various axial compressive strains, showing a decrease in the resonance frequency as estimated from the minimum value of the phase.

reading distance for the $\mathrm{Zn}$ pressure sensors was only about 6 $\mathrm{mm}$ (Figure $4 \mathrm{~d}$ ), whereas the $\mathrm{Mg}$ pressure sensors were relatively effortlessly readable at a distance of $10 \mathrm{~mm}$. The poorer performance of the $\mathrm{Zn}$ pressure sensors was likely caused by their lower conductor thickness, which resulted in a higher electrical resistance. Another potential reason is the arched cross-sectional profile of the $\mathrm{Zn}$ films, which may have decreased the quality of the resonance sensor due to increased parasitic capacitances or resistances.

The resonance peak of the $\mathrm{Zn}$-based sensors attenuated so considerably in Sörensen buffer solution that their resonance frequency was difficult to detect under immersion. Along with different corrosion behavior, this is another important reason why in vitro testing of bioresorbable LC circuits should not be performed in di- $\mathrm{H}_{2} \mathrm{O}$. Photographs illustrating the differences in sensor degradation are presented in Figure S3.

Although planar inductor coils are often used for flat resonance sensor architectures, orthopedic screws facilitate the implementation of solenoidal coil-based resonators. A similar idea has been demonstrated with nondegradable materials by embedding an LC circuit-based temperature sensor inside an interference screw for early detection of infections. ${ }^{8}$ In our study, a resonance compression sensor constructed by using parylene-insulated Mo wire (diameter $200 \mu \mathrm{m}$ ) is presented in Figure 4e. A reference sensor was fabricated by using commercial insulated $\mathrm{Cu}$ wire (diameter $180 \mu \mathrm{m}$ ).

The capacitor in the compression sensor composed of two turns of a double-stranded wire that was coiled along the screw threads, whereas the inductor coil was formed from a single Mo wire strand. Compressing the screw brings the turns between the wirings closer in both the inductor coil and the capacitor wirings, which leads to increased capacitances in the structure, which is noticed as a decreasing resonance frequency shift. For example, an axial compressive strain of $0.7 \%$ decreased the resonance frequency from 80.9 to $80.1 \mathrm{MHz}$ with a further drop to $79.6 \mathrm{MHz}$ at a strain of $1.4 \%$ (Figure $4 \mathrm{~g}$ ). This sensing capability could be applied for monitoring the dimensional changes in self-reinforced bioresorbable polymer screws, which are expected to swell and shorten 1$2 \%$ after implantation, thereby allowing improved compression at the bone fracture line. ${ }^{59}$ 

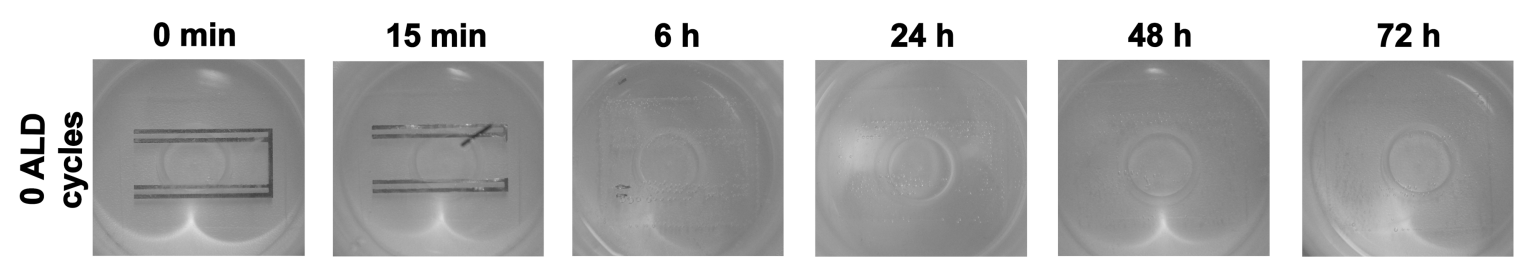

1 week
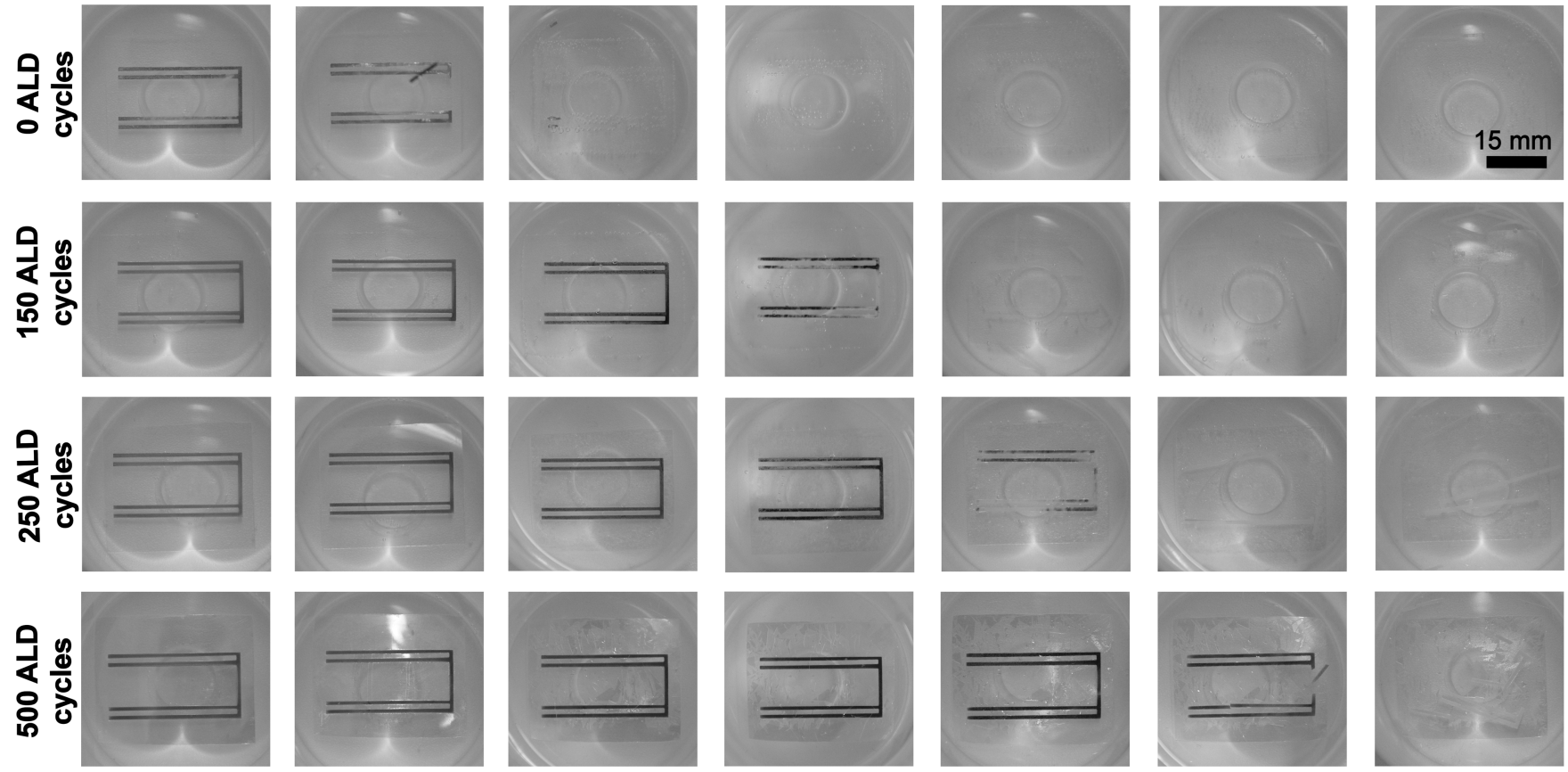

Figure 5. Atomic layer deposition (ALD) coated $\mathrm{Mg}$ conductors immersed in Sörensen phosphate buffer solution $(\mathrm{pH} 7.48)$ at $+37^{\circ} \mathrm{C}$. The $\mathrm{Mg}$ conductors $(7.5 \mu \mathrm{m})$ were deposited onto PLDLA 96/4 substrates and coated with different thicknesses of $\mathrm{TiO}_{2}$. One ALD cycle corresponded to $\sim 1 \AA$.

The resonance peak of the Mo-based device was noticed to be comparable to the $\mathrm{Cu}$ reference sensor (Figure $4 \mathrm{f}$ ). The Mo-based LC resonator was effortlessly readable with $10 \mathrm{~mm}$ of glass between the reader coil and the resonator. In this measurement setup, the tip of the screw (Figure 4e) increased the actual reading distance by $5 \mathrm{~mm}$. The inductance and capacitance of the resonator can be increased by adding more windings to the coil or the capacitor, respectively. Based on a preliminary immersion test using Sörensen buffer solution (37 ${ }^{\circ} \mathrm{C}$ ), uncoated Mo wires retained their electrical conductivity for $\sim 4$ weeks, after which the resistance started to increase (Figure S4). The first wire broke after 14 weeks of immersion. A previous immersion testing of Mo wire $(10 \mu \mathrm{m})$ in bovine serum has shown only a minor resistance increase during the 16 day test period. ${ }^{51}$ These findings demonstrate the potential of Mo in applications where a slow conductor degradation is preferred.

2.5. Encapsulation Layers. Achieving clinically relevant stable operation times of multiple days or weeks remains a challenge with implantable bioresorbable sensors. The dissolution or fracture of the conductors are among the main reasons for an untimely device failure along with disintegration of the device structure. ${ }^{14,49,60}$ Water penetration into the device is a common denominator for all of these breakdown mechanisms, for why separate water barrier layers have been studied to improve the stability of bioresorbable sensors. ${ }^{61,62}$ There is a great demand for encapsulation layers that could be applied onto bioresorbable polymer substrates because the deposition of inorganic coatings often requires elevated temperatures. In this section, the pros and cons of lowtemperature atomic layer deposited (ALD) $\mathrm{TiO}_{2}$ films on polymeric substrates are discussed. In addition, other options for increasing the functional lifetime of bioresorbable sensors are recapitulated.
Typical water barrier layers involve inorganic ceramic coatings like $\mathrm{SiO}_{2}, \mathrm{MgO}$, and $\mathrm{Si}_{3} \mathrm{~N}_{4}$ that are used in conventional electronics as well. Such coatings can be deposited for example by evaporation, sputtering, thermal oxidation, plasma-enhanced chemical vapor deposition (PECVD), or atomic layer deposition (ALD) methods. ${ }^{61,62}$ Kang et al. have studied different encapsulation layers and their combinations on silicon wafers, suggesting that some pinholes and other defects may be expected with PECVD deposited films despite their conformal nature, whereas ALD provides a means for reducing the amount of defects. ${ }^{61}$

Conventional PECVD processes are usually operated at temperatures around $250-350{ }^{\circ} \mathrm{C}$, even though room temperature processes have been also developed. ${ }^{61,63,64}$ Many ALD processes can be performed at lower temperatures, facilitating the use of polymeric substrates that typically require temperatures below $100{ }^{\circ} \mathrm{C} .^{65,66}$ However, there are only few studies where ALD coatings have been performed on biodegradable polymer substrates. ${ }^{67,68}$ In this study, the protective effect of ALD $\mathrm{TiO}_{2}$ on a $\mathrm{Mg}$ layer $(7.5 \mu \mathrm{m})$ evaporated onto bioresorbable PLDLA 96/4 substrates was studied. $\mathrm{TiO}_{2}$ was chosen as the coating material due to its excellent water corrosion resistance properties. ${ }^{69}$ The samples with different amounts $(0,150,250$, and 500) of ALD process cycles and thus different $\mathrm{TiO}_{2}$ thicknesses $(0,15,25$, and 50 $\mathrm{nm}$, respectively) were immersed in Sörensen buffer. The coatings were peeled off from the ends of the substrate (Figure S5) by using tape to enable water diffusion into the polymer, while keeping the coating on top of the $\mathrm{Mg}$ patterns intact. This simulated a realistic scenario, where the surgical insertion of an ALD coated implant would be difficult to perform without damaging the coating.

The noncoated $\mathrm{Mg}$ pattern disintegrated within the first minutes and was almost fully dissolved after $6 \mathrm{~h}$ of immersion (Figure 5). The ALD-coated $\mathrm{Mg}$ samples showed reduced 
dissolution rates with increasing $\mathrm{TiO}_{2}$ thicknesses, where the thickest coating $(\sim 50 \mathrm{~nm})$ resulted in an intact $\mathrm{Mg}$ pattern after 2 days of immersion. However, a black $\mathrm{Mg}$ surface layer possibly consisting of $\mathrm{Mg}(\mathrm{OH})_{2}$ was noticed earlier as a sign of corrosion, as described in $\mathrm{Mg}$ corrosion studies performed in atmospheric conditions. ${ }^{20}$ The corrosion could have been caused by the equilibrium water uptake into the PLDLA 96/4 substrates. Based on previous studies, using composite coatings formed from two or more different coating materials might provide improved water barrier properties. ${ }^{.1,69}$ Nonetheless, more studies are needed using bioresorbable substrates, as they significantly contribute to the functionality of the protective layer. For example, any dimensional changes in the substrates may potentially crack the coatings, as shown with an LC resonator formed using ALD-coated polymer substrates (Figure S6). Hence, in this kind of fully immersed and highly delicate sensor applications, ALD coatings might be more compatible with rigid substrates such as bioactive glasses. Inorganic coatings on rigid nondegradable wafers have been previously discussed in the literature. ${ }^{61,62,70}$

To avoid the challenges related to mechanical fragility of inorganic coatings, natural waxes have been described as a potential biodegradable encapsulation material option. ${ }^{51,71}$ The most promising reported candidate was candelilla wax that showed hardly any water uptake during the first 2 weeks of immersion. A $300 \mu \mathrm{m}$ thick wax layer helped $\mathrm{Mg}$ patterns retain their conductivity for more than 7 days in phosphate buffer solution (PBS). ${ }^{71}$ Further advances have been recently reported by blending different waxes. The combination of transfer printed monocrystalline silicon layers together with edge-sealing wax barriers enabled accurate ICP measurements in rats for up to 3 weeks using a wired bioresorbable sensor. ${ }^{72}$ Furthermore, recent advances in gas-phase polymerization of hydrolytically degradable polymers could in the future provide bioresorbable conformal coatings similar to nondegradable parylene, which has already been utilized in passivation coatings of implanted devices. ${ }^{73}$

A common scheme for protecting bioresorbable circuitry is to use sensor substrates as encapsulation layers. Most of the reported bioresorbable polymers are bulk-degrading, which means that water diffuses into the polymer matrix at a faster speed than the polymer erodes. ${ }^{74}$ For example, the equilibrium water uptake of immersed polyesters is around $1 \mathrm{wt} \%{ }^{36}$ Even such a small amount of water leads to corrosion of the metal conductors over time and may affect the dimensional properties of the polymer. One interesting possibility to circumvent this problem is to use surface-eroding polymers like poly(ortho esters) or polyanhydrides, where water diffusion into the polymer matrix is slower than the erosion rate of the material. ${ }^{74}$ As an example, polyanhydride coating $(120 \mu \mathrm{m})$ has been shown to enable a stable operation of 3 days for a silicon semiconductor-based pressure sensor. ${ }^{10}$ Nevertheless, the effects of surface-eroding substrates on wireless LC circuitbased sensors remains to be tested.

\section{EXPERIMENTAL SECTION}

3.1. Device Fabrication. The $\mathrm{Mg}$ and $\mathrm{Zn}$ pressure sensors whose structure was illustrated in Figure la were fabricated by extruding PDTEC powder (Integra LifeSciences, Princeton, NJ) and compression-molding pieces of the extruded rod into plates (430 $\mu \mathrm{m})$. PDTEC spacers $(50-70 \mu \mathrm{m})$ were compression-molded and laser-cut as described earlier. ${ }^{18}$ Compression-molded PCL layers $(15-20 \mu \mathrm{m})$ were melted onto both sides of the spacer, and excessive
PCL was removed from the laser-cut holes. E-beam-evaporated Mg $(7.5 \mu \mathrm{m})$ or magnetron-sputtered $\mathrm{Zn}(4 \mu \mathrm{m})$ conductors were deposited onto the PDTEC substrates through laser-cut steel masks, after which the substrates were attached onto the spacer by heating the structure to $80{ }^{\circ} \mathrm{C}$ and using the molten PCL layers as an adhesive. The sides of the sensors were finally heat sealed (Hawo HPL ISZ, Obrigheim, Germany) and trimmed with scissors to yield sensors sized approximately $1 \mathrm{~mm}$ by $25 \mathrm{~mm}$ by $35 \mathrm{~mm}$. A simplified electrical model of a resonator based on a similar pattern has been reported earlier. ${ }^{75}$

The wireless compression sensors (Figure 4e) based on parylenecoated Mo wire $(200 \mu \mathrm{m})$ conductors were fabricated by extruding PLDLA $96 / 4$ into a rod $(\phi=10 \mathrm{~mm})$, threading the rod, and cutting it into billets. The Mo wire was coated with nondegradable parylene C (10 $\mu \mathrm{m}$; Galentis S.r.l., Italy) to prevent short circuit. Two holes were drilled through each billet to provide electrical vias for the construct and to aid in fixing the wire to the threaded billet. A solenoidal coil was formed by winding Mo wire around the billet (5.5 turns). The capacitor was formed by coiling double-stranded wire along the threads ( 2 turns). The loose double-stranded wire ending was attached to the billet by using molten PCL as an adhesive. Reference resonators were fabricated in a similar manner using commercial enamel insulated $\mathrm{Cu}$ wire $(180 \mu \mathrm{m})$.

The bioactive glass resonance sensors (Figure $2 b$ ) were made from silicate $\mathrm{S} 53 \mathrm{P} 4$ glass that was prepared by a conventional glass melting method in platinum crucible. The nominal oxide composition of S53P4 is 53 wt $\% \mathrm{SiO}_{2}, 23$ wt $\% \mathrm{Na}_{2} \mathrm{O}, 20$ wt $\% \mathrm{CaO}$, and 4 wt $\%$ $\mathrm{P}_{2} \mathrm{O}_{5} .{ }^{76}$ In this study, proportional amounts of $\mathrm{SiO}_{2}, \mathrm{CaCO}_{3}, \mathrm{Na}_{2} \mathrm{CO}_{3}$, and $\mathrm{CaHPO}_{4} \cdot 2 \mathrm{H}_{2} \mathrm{O}$ raw materials were used. The mixture was melted at $1450{ }^{\circ} \mathrm{C}$, cast and quenched in a prewarmed $\left(350{ }^{\circ} \mathrm{C}\right)$ graphite mold, and annealed at $520{ }^{\circ} \mathrm{C}$ for $5 \mathrm{~h}$. The resulting S53P4 bioactive glass rods $(\phi=14 \mathrm{~mm})$ were sliced into discs $(h=2 \mathrm{~mm})$ which were polished. E-beam-evaporated $\mathrm{Mg}(7.5 \mu \mathrm{m})$ formed the first conductor layer, after which PDTEC solution (12\%) in cyclohexanone (VWR Chemicals, Fontenay-sous-Bois, France) was spin-coated onto the discs. 3D-printed masks were used to define the Mg patterns. Another Mg layer $(7.5 \mu \mathrm{m})$ was evaporated onto the dielectric PDTEC layer to complete the resonator. The resonators were finally parylene coated $(13 \mu \mathrm{m})$ to enable studying the resonator behavior in aqueous conditions without constraints related to $\mathrm{Mg}$ corrosion.

3.2. Physical Vapor Deposition. E-beam evaporation of $\mathrm{Mg}$ granules (99.99\%; G-materials, Germany) was performed at less than $7 \times 10^{-6}$ Torr with substrate rotation. The source-to-substrate distance was $31 \mathrm{~cm}$. The $\mathrm{Zn}$ films were deposited from a $\mathrm{Zn}$ target (99.99\% Zn; Kurt J. Lesker Company, Hastings, UK) by using direct current (DC) magnetron sputtering. The vacuum level was $5 \times 10^{-6}$ Torr with a working Ar gas pressure of $10 \mathrm{mTorr}$. The sputtering current and voltage were $1 \mathrm{~A}$ and $560 \mathrm{~V}$, respectively. The sputtering target-to-substrate distance was $10.5 \mathrm{~cm}$. No substrate rotation was used.

3.3. Thin Film Characterization. The cross-sectional structure of the $\mathrm{Mg}(7.5 \mu \mathrm{m})$ and $\mathrm{Zn}(4 \mu \mathrm{m})$ films on bioresorbable PDTEC substrates was analyzed with a scanning electron microscope (SEM) combined with focused ion beam milling (FIB-SEM; Zeiss CrossBeam 540) from a working distance of $5.2 \mathrm{~mm}$ with an electron high tension (EHT) of $3.0 \mathrm{kV}$. A platinum cover was applied onto the target films before gallium ion milling. The surface of the metal films was imaged with a high-resolution field emission SEM (FESEM; Zeiss UltraPlus) from a working distance of $5.0 \pm 0.2 \mathrm{~mm}$ and with an EHT of $1.5 \mathrm{kV}$. The surface topography of the metal films was further characterized by using a noncontact atomic force microscope (AFM; XE-100, Park Systems Inc., USA) equipped with silicon probes (ACTa, Applied NanoStructures Inc., USA). The imaged area with the AFM was $5 \times 5 \mu \mathrm{m}^{2}$.

The height and the cross-sectional profile of the $\mathrm{Mg}$ and $\mathrm{Zn}$ films $(1.7 \mu \mathrm{m})$ on glass slides (Figure $3 \mathrm{~b}$ ) was measured by using a mechanical profiler (Dektak XT Stylus, Bruker Corporation). The electrical resistance $(\Omega / \mathrm{cm})$ of these films was calculated by dividing the measured resistance of the deposited 4-wire patterns $(n=6)$ by the distance between the inner lines of the pattern (Figure 3c). Mean 
bulk resistivity of the $1.7 \mu \mathrm{m}$ thick films was approximated by multiplying the mean electrical resistance values with the estimated conductor cross-sectional area. Based on the profilometer data, the width of the $\mathrm{Mg}$ conductor films was estimated at $1 \mathrm{~mm}$, and the cross-sectional area of the $\mathrm{Zn}$ films was considered similar to that of the $\mathrm{Mg}$ films. Finally, the samples were immersed in $25 \mathrm{~mL}$ of cell culture medium (MEM; Sigma-Aldrich supplemented with $10 \%$ fetal bovine serum and $1 \%$ antibiotics) at $+37{ }^{\circ} \mathrm{C}$ with a $5 \% \mathrm{CO}_{2}$ supply and photographed at predetermined time points for corrosion behavior comparison (Figure 3d). In addition, thicker $\mathrm{Mg}$ samples $(7.5 \mu \mathrm{m})$ were immersed in similar cell culture conditions as well as in $25 \mathrm{~mL}$ of di- $\mathrm{H}_{2} \mathrm{O}$ and Sörensen buffer $\left(+37^{\circ} \mathrm{C}\right)$ to compare different corrosive environments (Figure S2).

3.4. Wireless Measurements. The reading distance of all LC circuit-based sensors was investigated by using the same measurement setup, which included a double-turn square reader coil (diameter about $20 \mathrm{~mm}$ ) on a printed circuit board (PCB). ${ }^{45}$ The reading distance was stepwise increased by adding $1 \mathrm{~mm}$ glass slides between the reader coil and the sensor. After each $1 \mathrm{~mm}$ increment, the real part of the impedance of the reader coil was measured with an impedance analyzer (Agilent 4396B). Furthermore, the miniaturized bioactive glass-based sensor was measured 100 times at each discrete distance to obtain the mean and standard deviation of the resonance frequency, similarly to our previous $\mathrm{Mg}$ pressure sensor. ${ }^{18}$

The other wireless measurements were performed by using setups that were constructed on occasion depending on the type of measurement. The reader coils were chosen to increase the coupling coefficients between the sensors and the reader coils. The $\mathrm{Mg}$ and $\mathrm{Zn}$ pressure sensors were measured using a similar setup as described earlier, where a single-turn copper reader coil $(\phi=33 \mathrm{~mm})$ was located inside an oven and connected to the impedance analyzer with a cable. ${ }^{18}$ The sensors were taped onto the bottom of a glass bottle, which was pressurized from 0 to $200 \mathrm{mmHg}$ applied pressure in increments of $20 \mathrm{mmHg}$ by using a manual pressure regulator connected to a pressure calibrator. The reading distance through the glass bottle was $\sim 6 \mathrm{~mm}$. The immersion tests were performed by pouring $100 \mathrm{~mL}$ of buffer solution into the bottle and measuring the resonance frequency every $15 \mathrm{~min}$. In addition, the pressure response of the sensor was measured during immersion at predetermined time points.

The wireless compression sensor built onto a PLDLA 96/4 screw was axially compressed in a vise by using an electrically insulating Teflon block between the reader coil and the metallic vise jaw. As opposed to other measurements that were performed with an impedance analyzer, the resonance frequency of the compression sensor was determined by using an in-house built portable reader device. $^{77}$ The reader coil was a single turn aluminum coil with a diameter of $30 \mathrm{~mm}$ on a poly(ethylene terephthalate) (PET) sheet. The measurements were performed by using the phase-dip method, where the resonance frequency was the estimated minimum value in the phase of impedance. ${ }^{77}$ The compression was measured by using a digital caliper.

The parylene-coated bioactive glass resonance sensors were measured through a $1 \mathrm{~mm}$ thick Petri dish by using the double-turn rectangular reader coil. The resonators were first immersed in di- $\mathrm{H}_{2} \mathrm{O}$ and measured, after which $9 \% \mathrm{NaCl}$ solution was stepwise added until the solution reached a $\mathrm{NaCl}$ concentration of $4.5 \%$. After each addition of the $\mathrm{NaCl}$ solution, the mixture was gently suspended using a pipet to ensure that the solution was homogeneous. The response of the sensor was recorded after each $\mathrm{NaCl}$ addition step. To test the effect of the immersion media onto the sensor, 200 measurement samples were recorded in air and under immersion in di- $\mathrm{H}_{2} \mathrm{O}$, Sörensen phosphate buffer, DMEM with high glucose (Sigma-Aldrich, United Kingdom), and 96\% ethanol (VWR Chemicals). The sensor was rinsed with di- $\mathrm{H}_{2} \mathrm{O}$ and tapped dry with tissue paper between each solution.

3.5. Water Uptake Testing of Polymers. The water uptake properties of PDTEC were evaluated by using samples $(n=5)$ with a size of $50 \times 10 \times 0.4 \mathrm{~mm}^{3}$. The samples were dried in a vacuum, weighed, and then immersed in Sörensen buffer solution at $37^{\circ} \mathrm{C}$. At predetermined time points, the samples were gently wiped with tissue paper and weighed. The wet weights were compared to the initial dry weight. After 100 days of immersion, the hydrolysis was terminated by rinsing the samples with di- $\mathrm{H}_{2} \mathrm{O}$, drying them thoroughly in a vacuum, and weighing to ensure that no mass loss had occurred.

3.6. Mechanical Testing. Flexural characteristics of PDTEC were determined by testing the stress-strain and the stress relaxation behavior of the material with an Instron Electropuls E1000 testing machine (High Wycombe, UK) equipped with a $50 \mathrm{~N}$ load cell. The span length of the three-point bending setup was $30 \mathrm{~mm}$, and the sample size was $50 \times 10 \times 0.9 \mathrm{~mm}^{3}$. The stress-strain behavior of samples $(n=3)$ was obtained by bending the samples with a $5 \mathrm{~mm} /$ min crosshead speed until $5 \%$ flexure strain was reached. The tests were performed in ambient laboratory conditions as well as in aqueous conditions (Figure 1f) after different immersion times. Young's moduli were calculated from the linear portion of the acquired stress-strain curves. The stress relaxation behavior of the PDTEC samples $(n=3)$ was tested under immersion (Sörensen buffer, $+37^{\circ} \mathrm{C}$ ) by bending the sample rapidly to $2 \mathrm{~mm}$ displacement and holding it for $3 \mathrm{~h}$. The stress needed to hold the displacement was recorded with respect to time.

3.7. ALD Coating. The $7.5 \mu \mathrm{m}$ thick $\mathrm{Mg}$ patterns were e-beam evaporated onto compression-molded PLDLA 96/4 substrates (0.4 $\mathrm{mm} \times 30 \mathrm{~mm} \times 40 \mathrm{~mm}$ ). Thereafter, ALD $\mathrm{TiO}_{2}$ coatings were deposited onto the metallized substrates at $60{ }^{\circ} \mathrm{C}$ by using a Beneq TFS 200 ALD reactor. ALD $\mathrm{TiO}_{2}$ films were grown from titanium tetrachloride $\left(\mathrm{TiCl}_{4}\right)$ (Sigma-Aldrich) and water, both vaporized from the source at $20^{\circ} \mathrm{C}$. One deposition cycle for $\mathrm{TiO}_{2}$ consisted of a $0.5 \mathrm{~s}$ $\mathrm{TiCl}_{4}$ pulse, a $20 \mathrm{~s} \mathrm{~N}_{2}$ purge, a $0.5 \mathrm{~s}$ water pulse, and a $20 \mathrm{~s} \mathrm{~N}_{2}$ purge. The ALD $\mathrm{TiO}_{2}$ film thickness was varied by alternating the number of ALD cycles. The amount of cycles was 150, 250, and 500. Each ALD cycle corresponded to about $1 \AA$. The film thicknesses were measured from silicon (100) witness pieces by using spectroscopic ellipsometry (J.A. Woollam Co., Inc., model M-2000FI).

\section{CONCLUSIONS AND FUTURE CONSIDERATIONS}

This study summarizes the prospects and caveats in the assembly, testing, and performance of wireless inductorcapacitor (LC) resonance sensors fabricated by using bioresorbable materials, as well as outlines several potential orthopedic applications for such devices. The reported Mgbased pressure sensors were wirelessly readable and pressure responsive for 10 days in aqueous conditions, but water diffusion into the bulk-degrading polymer substrates resulted in sensitivity and baseline resonance frequency drifting. Using surface-eroding materials or separate encapsulation layers to hinder water diffusion into the substrates should thereby be considered to enable stable operation during the functional lifetime of the sensor. In our opinion, bioactive glasses possess tremendous undiscovered potential in bioresorbable sensors, including possible improvements in their stability. Moreover, these glasses tolerate conventional microfabrication techniques better than most biodegradable polymers, which provides prospective opportunities for device fabrication and assembly. The reported resonance sensors operate at distances that are sufficient for applications close beneath the skin. Longer reading distances could be achieved for instance by using thicker conductors or developing bioresorbable materials with improved electrical conductivities. However, depending on the material, thick films may be difficult to produce by physical vapor deposition (PVD), and the obtained thin film conductivities are often lower than those of the bulk materials. Thus, PVD might not be the ideal conductor fabrication method for maximizing the reading distances. Although $\mathrm{Mg}$ is the most studied biodegradable metal with the highest conductivity in this material group, $\mathrm{Zn}$ and Mo provide slower 
corroding options whose potential should be more thoroughly investigated.

\section{ASSOCIATED CONTENT}

\section{SI Supporting Information}

The Supporting Information is available free of charge at https://pubs.acs.org/doi/10.1021/acsami.0c07278.

Cell culture results, discussion and experimental methods; skin depths of common bioresorbable materials; corrosion testing of magnesium films (7.5 $\mu \mathrm{m})$; in vitro degradation of wireless $\mathrm{Mg}$ and $\mathrm{Zn}$ pressure sensors; molybdenum wire $(200 \mu \mathrm{m})$ immersion test; illustration of the peeled-off area of the ALD coatings; ALD-coated substrates in an LC resonator (PDF)

\section{AUTHOR INFORMATION}

\section{Corresponding Author}

Aleksi Palmroth - BioMediTech, Faculty of Medicine and

Health Technology, Tampere University, Tampere 33720,

Finland; (1) orcid.org/0000-0002-8574-6922;

Email: aleksi.palmroth@tuni.fi

\section{Authors}

Timo Salpavaara - BioMediTech, Faculty of Medicine and Health Technology, Tampere University, Tampere 33720, Finland

Petri Vuoristo - Materials Science and Environmental Engineering, Faculty of Engineering and Natural Sciences, Tampere University, Tampere 33720, Finland

Sanna Karjalainen - BioMediTech, Faculty of Medicine and Health Technology, Tampere University, Tampere 33720, Finland

Tommi Kääriäinen - Department of Chemistry, University of Colorado Boulder, Boulder, Colorado 80309, United States

Susanna Miettinen - BioMediTech, Faculty of Medicine and Health Technology, Tampere University, Tampere 33720, Finland

Jonathan Massera - BioMediTech, Faculty of Medicine and Health Technology, Tampere University, Tampere 33720, Finland; orcid.org/0000-0002-1099-8420

Jukka Lekkala - BioMediTech, Faculty of Medicine and Health Technology, Tampere University, Tampere 33720, Finland

Minna Kellomäki - BioMediTech, Faculty of Medicine and Health Technology, Tampere University, Tampere 33720, Finland

Complete contact information is available at: https://pubs.acs.org/10.1021/acsami.0c07278

\section{Funding}

The study was funded by Business Finland (Human Spare Parts project) and by the Finnish Cultural Foundation's Kalle and Dagmar Välimaa fund.

\section{Notes}

The authors declare no competing financial interest.

\section{ACKNOWLEDGMENTS}

The authors acknowledge Timo Allinniemi and Jukka Lukkariniemi for their advice regarding the study. Heikki Liejumäki and Suvi Heinämäki are thanked for their technical assistance in the biomaterial studies. We also thank Anna-Maija Honkala and Sari Kalliokoski for technical assistance in cell culture experiments as well as Nina Sandberg for her efforts in preparing the cell culture discs. This work made use of Tampere Microscopy Center facilities at Tampere University.

\section{REFERENCES}

(1) Ledet, E. H.; D’Lima, D.; Westerhoff, P.; Szivek, J. A.; Wachs, R. A.; Bergmann, G. Implantable Sensor Technology: From Research to Clinical Practice. J. Am. Acad. Orthop. Surg. 2012, 20 (6), 383.

(2) Boutry, C. M.; Chandrahalim, H.; Streit, P.; Schinhammer, M.; Hänzi, A. C.; Hierold, C. Towards Biodegradable Wireless Implants. Philos. Trans. R. Soc. A Math. Phys. Eng. Sci. 2012, 370 (1967), 24182432.

(3) Boutry, C. M.; Beker, L.; Kaizawa, Y.; Vassos, C.; Tran, H.; Hinckley, A. C.; Pfattner, R.; Niu, S.; Li, J.; Claverie, J.; Wang, Z.; Chang, J.; Fox, P. M.; Bao, Z. Biodegradable and Flexible ArterialPulse Sensor for the Wireless Monitoring of Blood Flow. Nat. Biomed. Eng. 2019, 3 (1), 47-57.

(4) Ledet, E. H.; Liddle, B.; Kradinova, K.; Harper, S. Smart Implants in Orthopedic Surgery, Improving Patient Outcomes: A Review. Innov. Entrep. Heal. 2018, 5, 41-51.

(5) Li, R.; Wang, L.; Kong, D.; Yin, L. Recent Progress on Biodegradable Materials and Transient. Electronics. Bioact. Mater. 2018, 3 (3), 322-333.

(6) La Mattina, A. A.; Mariani, S.; Barillaro, G. Bioresorbable Materials on the Rise: From Electronic Components and Physical Sensors to In Vivo Monitoring Systems. Adv. Sci. 2020, 7 (4), 1902872.

(7) Huang, Q. A.; Dong, L.; Wang, L. F. LC Passive Wireless Sensors Toward a Wireless Sensing Platform: Status, Prospects, and Challenges. J. Microelectromech. Syst. 2016, 25 (5), 822-841.

(8) Karipott, S. S.; Veetil, P. M.; Nelson, B. D.; Guldberg, R. E.; Ong, K. G. An Embedded Wireless Temperature Sensor for Orthopedic Implants. IEEE Sens. J. 2018, 18 (3), 1265-1272.

(9) Boutry, C. M.; Kaizawa, Y.; Schroeder, B. C.; Chortos, A.; Legrand, A.; Wang, Z.; Chang, J.; Fox, P.; Bao, Z. A Stretchable and Biodegradable Strain and Pressure Sensor for Orthopaedic Application. Nat. Electron. 2018, 1 (5), 314-321.

(10) Kang, S.-K.; Murphy, R. K. J.; Hwang, S.-W.; Lee, S. M.; Harburg, D. V.; Krueger, N. A.; Shin, J.; Gamble, P.; Cheng, H.; Yu, S.; Liu, Z.; McCall, J. G.; Stephen, M.; Ying, H.; Kim, J.; Park, G.; Webb, C.; Lee, C. H.; Chung, S.; Wie, D. S.; Gujar, A. D.; Vemulapalli, B.; Kim, A. H.; Lee, K.-M.; Cheng, J.; Huang, Y.; Lee, S. H.; Braun, P. V.; Ray, W. Z.; Rogers, J. A. Bioresorbable Silicon Electronic Sensors for the Brain. Nature 2016, 530 (7588), 71-76.

(11) Gustke, K. A.; Golladay, G. J.; Roche, M. W.; Jerry, G. J.; Elson, L. C.; Anderson, C. R. Increased Satisfaction after Total Knee Replacement Using Sensor-Guided Technology. Bone Joint J. 2014, 96-B (10), 1333-1338.

(12) O'Connor, C.; Kiourti, A. Wireless Sensors for Smart Orthopedic Implants. J. Bio- Tribo-Corrosion 2017, 3 (2), 20.

(13) Allen, M. G. Micromachined Endovascularly-Implantable Wireless Aneurysm Pressure Sensors: From Concept to Clinic. In The 13th International Conference on Solid-State Sensors, Actuators and Microsystems, 2005. Digest of Technical Papers. TRANSDUCERS '05; 2005; Vol. 1, pp 275-278 .

(14) Yu, X.; Shou, W.; Mahajan, B. K.; Huang, X.; Pan, H. Materials, Processes, and Facile Manufacturing for Bioresorbable Electronics: A Review. Adv. Mater. 2018, 30 (28), 1707624.

(15) Luo, M.; Martinez, A. W.; Song, C.; Herrault, F.; Allen, M. G. A Microfabricated Wireless RF Pressure Sensor Made Completely of Biodegradable Materials. J. Microelectromech. Syst. 2014, 23, 4-13.

(16) Hänninen, A.; Salpavaara, T.; Lekkala, J.; Kellomäki, M. An Inductively Coupled Biodegradable Capacitive Pressure Sensor. Proceedings. 2018.

(17) Luo, M.; Shen, W.; Allen, M. G. Microfabricated PLGA/PVABased Completely Biodegradable Passive RF Pressure Sensors. In 2015 Transducers - 2015 18th International Conference on Solid-State 
Sensors, Actuators and Microsystems (TRANSDUCERS); 2015; pp 101-104.

(18) Palmroth, A.; Salpavaara, T.; Lekkala, J.; Kellomäki, M. Fabrication and Characterization of a Wireless Bioresorbable Pressure Sensor. Adv. Mater. Technol. 2019, o (0), 1900428.

(19) Eppley, B. L. Use of Resorbable Plates and Screws in Pediatric Facial Fractures. J. Oral Maxillofac. Surg. 2005, 63 (3), 385-391.

(20) Gonzalez, J.; Hou, R. Q.; Nidadavolu, E. P. S.; WillumeitRömer, R.; Feyerabend, F. Magnesium Degradation under Physiological Conditions - Best Practice. Bioact. Mater. 2018, 3 (2), 174185.

(21) Chen, P.; Saati, S.; Varma, R.; Humayun, M. S.; Tai, Y. Wireless Intraocular Pressure Sensing Using Microfabricated Minimally Invasive Flexible-Coiled LC Sensor Implant. J. Microelectromech. Syst. 2010, 19 (4), 721-734.

(22) Marco, I.; Feyerabend, F.; Willumeit-Römer, R.; Van der Biest, O. Degradation Testing of Mg Alloys in Dulbecco's Modified Eagle Medium: Influence of Medium Sterilization. Mater. Sci. Eng., C 2016, $62,68-78$.

(23) Tangpasuthadol, V.; Pendharkar, S. M.; Peterson, R. C.; Kohn, J. Hydrolytic Degradation of Tyrosine-Derived Polycarbonates, a Class of New Biomaterials. Part II: 3-Yr Study of Polymeric Devices. Biomaterials 2000, 21 (23), 2379-2387.

(24) Seruya, M.; Oh, A. K.; Boyajian, M. J.; Posnick, J. C.; Keating, R. F. Treatment for Delayed Presentation of Sagittal Synostosis: Challenges Pertaining to Occult Intracranial Hypertension. J. Neurosurg. Pediatr. 2011, 8 (1), 40-48.

(25) Schmidt, A. H. Acute Compartment Syndrome. Injury 2017, 48, S22-S25.

(26) Popkov, A. V.; Popkov, D. A.; Kononovich, N. A.; Gorbach, E. N.; Tverdokhlebov, S. I.; Bolbasov, E. N.; Darvin, E. O. Biological Activity of the Implant for Internal Fixation. J. Tissue Eng. Regener. Med. 2018, 12 (12), 2248-2255.

(27) Jones, J. R. Review of Bioactive Glass: From Hench to Hybrids. Acta Biomater. 2013, 9 (1), 4457-4486.

(28) Unda, K.; Mohammadkhah, A.; Lee, K.; Day, D. E.; O’Keefe, M. J.; Kim, C. Sensor Substrates Based on Biodegradable Glass Materials. 2016 IEEE SENSORS 2016, 1-3.

(29) Adnan, S.; Lee, K.-M.; Ghasr, M. T.; O’Keefe, M. J.; Day, D. E.; Kim, C.-S. Water-Soluble Glass Substrate as a Platform for Biodegradable Solid-State Devices. IEEE J. Electron Devices Soc. 2016, 4 (6), 490-494.

(30) Collins, C. Miniature Passive Pressure Transensor for Implanting in the Eye. IEEE Trans. Biomed. Eng. 1967, BME-14 (2), 74-83.

(31) Chen, L. Y.; Tee, B. C.-K.; Chortos, A. L.; Schwartz, G.; Tse, V.; J. Lipomi, D.; Wong, H.-S. P.; McConnell, M. V.; Bao, Z. Continuous Wireless Pressure Monitoring and Mapping with UltraSmall Passive Sensors for Health Monitoring and Critical Care. Nat. Commun. 2014, 5, 1-10.

(32) Baù, M.; Demori, M.; Ferrari, M.; Ferrari, V. Contactless Readout of Passive LC Sensors with Compensation Circuit for Distance-Independent Measurements. Proceedings 2018, 2, 842.

(33) Ong, K. G.; Grimes, C. A.; Robbins, C. L.; Singh, R. S. Design and Application of a Wireless, Passive, Resonant-Circuit Environmental Monitoring Sensor. Sens. Actuators, A 2001, 93 (1), 33-43.

(34) Salpavaara, T.; Järveläinen, M.; Yli-Hallila, T.; Seppälä, S.; Levänen, E.; Vilkko, M.; Lekkala, J. Passive Resonance Sensor Based Method for Monitoring Particle Suspensions. Sensors Actuators B. Chem. 2014, 219, 324-330.

(35) Yvanoff, M.; Venkataraman, J. A Feasibility Study of Tissue Characterization Using LC Sensors. IEEE Trans. Antennas Propag. 2009, 57 (4), 885-893.

(36) Salpavaara, T.; Hänninen, A.; Antniemi, A.; Lekkala, J.; Kellomäki, M. Non-Destructive and Wireless Monitoring of Biodegradable Polymers. Sens. Actuators, B 2017, 251, 1018-1025.

(37) Peltola, M.; Kinnunen, I.; Aitasalo, K. Reconstruction of Orbital Wall Defects With Bioactive Glass Plates. J. Oral Maxillofac. Surg. 2008, 66 (4), 639-646.
(38) Rüegg, M.; Blum, R.; Boero, G.; Brugger, J. Biodegradable Frequency-Selective Magnesium Radio-Frequency Microresonators for Transient Biomedical Implants. Adv. Funct. Mater. 2019, 1903051.

(39) Yin, L.; Cheng, H.; Mao, S.; Haasch, R.; Liu, Y.; Xie, X.; Hwang, S.-W.; Jain, H.; Kang, S.-K.; Su, Y.; Li, R.; Huang, Y.; Rogers, J. A. Dissolvable Metals for Transient Electronics. Adv. Funct. Mater. 2014, 24 (5), 645-658.

(40) Kim, Y.-J.; Allen, M. G. Surface Micromachined Solenoid Inductors for High Frequency Applications. IEEE Trans. Components, Packag. Manuf. Technol. Part C 1998, 21 (1), 26-33.

(41) Boutry, C. M.; Chandrahalim, H.; Streit, P.; Schinhammer, M.; Hänzi, A. C.; Hierold, C. Characterization of Miniaturized RLC Resonators Made of Biodegradable Materials for Wireless Implant Applications. Sens. Actuators, A 2013, 189, 344-355.

(42) Zeng, J.; Wang, C.; Sangster, A. J. Theoretical and Experimental Studies of Flip-Chip Assembled High-Q Suspended MEMS Inductors. IEEE Trans. Microwave Theory Technol. 2007, 55 (6), 1171-1181.

(43) Hwang, S.-W.; Huang, X.; Seo, J.-H.; Song, J.-K.; Kim, S.; HageAli, S.; Chung, H.-J.; Tao, H.; Omenetto, F. G.; Ma, Z.; Rogers, J. A. Materials for Bioresorbable Radio Frequency Electronics. Adv. Mater. 2013, 25 (26), 3526-3531.

(44) Lee, C. H.; Kang, S.-K.; Salvatore, G. A.; Ma, Y.; Kim, B. H.; Jiang, Y.; Kim, J. S.; Yan, L.; Wie, D. S.; Banks, A.; Oh, S. J.; Feng, X.; Huang, Y.; Troester, G.; Rogers, J. A. Wireless Microfluidic Systems for Programmed, Functional Transformation of Transient Electronic Devices. Adv. Funct. Mater. 2015, 25 (32), 5100-5106.

(45) Palmroth, A.; Salpavaara, T.; Lyyra, I.; Kroon, M.; Lekkala, J.; Kellomäki, M. Bioresorbable Conductive Wire with Minimal Metal Content. ACS Biomater. Sci. Eng. 2019, 5, 1134.

(46) Martin, P. M.. Handbook of Deposition Technologies for Films and Coatings: Science, Applications and Technology; William Andrew: 2009.

(47) Moens, F.; Schramm, I. C.; Konstantinidis, S.; Depla, D. On the Microstructure of Magnesium Thin Films Deposited by Magnetron Sputtering. Thin Solid Films 2019, 689, 137501.

(48) Rossnagel, S. M. Thin Film Deposition with Physical Vapor Deposition and Related Technologies. J. Vac. Sci. Technol., A 2003, 21 (5), S74-S87.

(49) Hwang, S.-W.; Song, J.-K.; Huang, X.; Cheng, H.; Kang, S.-K.; Kim, B. H.; Kim, J.-H.; Yu, S.; Huang, Y.; Rogers, J. A. HighPerformance Biodegradable/Transient Electronics on Biodegradable Polymers. Adv. Mater. 2014, 26 (23), 3905-3911.

(50) Lee, C. H.; Kim, H.; Harburg, D. V.; Park, G.; Ma, Y.; Pan, T.; Kim, J. S.; Lee, N. Y.; Kim, B. H.; Jang, K.-I.; Kang, S.-K.; Huang, Y.; Kim, J.; Lee, K.-M.; Leal, C.; Rogers, J. A. Biological Lipid Membranes for On-Demand, Wireless Drug Delivery from Thin, Bioresorbable Electronic Implants. Npg Asia Mater. 2015, 7, 1-9.

(51) Koo, J.; MacEwan, M. R.; Kang, S.-K.; Won, S. M.; Stephen, M.; Gamble, P.; Xie, Z.; Yan, Y.; Chen, Y.-Y.; Shin, J.; Birenbaum, N.; Chung, S.; Kim, S. B.; Khalifeh, J.; Harburg, D. V.; Bean, K.; Paskett, M.; Kim, J.; Zohny, Z. S.; Lee, S. M.; Zhang, R.; Luo, K.; Ji, B.; Banks, A.; Lee, H. M.; Huang, Y.; Ray, W. Z.; Rogers, J. A. Wireless Bioresorbable Electronic System Enables Sustained Nonpharmacological Neuroregenerative Therapy. Nat. Med. 2018, 24 (12), 18301836.

(52) Allen, D.; Simpkins, M.; Almond, H. A Novel Photochemical Machining Process for Magnesium Aerospace and Biomedical Microengineering Applications. J. Micromech. Microeng. 2010, 20, 105010.

(53) Guo, Q.; Koo, J.; Xie, Z.; Avila, R.; Yu, X.; Ning, X.; Zhang, H.; Liang, X.; Kim, S. B.; Yan, Y.; MacEwan, M. R.; Lee, H. M.; Song, A.; Di, Z.; Huang, Y.; Mei, Y.; Rogers, J. A. A Bioresorbable Magnetically Coupled System for Low-Frequency Wireless Power Transfer. Adv. Funct. Mater. 2019, 0 (0), 1905451.

(54) Tsang, M.; Armutlulu, A.; Herrault, F.; Shafer, R. H.; Allen, S. A. B.; Allen, M. G. Development of Electroplated Magnesium Microstructures for Biodegradable Devices and Energy Sources. J. Microelectromech. Syst. 2014, 23 (6), 1281-1289.

(55) Lee, S.; Koo, J.; Kang, S.-K.; Park, G.; Lee, Y. J.; Chen, Y.-Y.; Lim, S. A.; Lee, K.-M.; Rogers, J. A. Metal Microparticle - Polymer 
Composites as Printable, Bio/Ecoresorbable Conductive Inks. Mater. Today 2018, 21 (3), 207-215.

(56) Abduev, A. K.; Akhmedov, A. K.; Asvarov, A. S.; Alikhanov, N. M.-R.; Emirov, R. M.; Muslimov, A. E.; Belyaev, V. V. Gas-Phase Clusterization of Zinc during Magnetron Sputtering. Crystallogr. Rep. 2017, 62 (1), 133-138.

(57) Vojtěch, D.; Kubásek, J.; Šerák, J.; Novák, P. Mechanical and Corrosion Properties of Newly Developed Biodegradable Zn-Based Alloys for Bone Fixation. Acta Biomater. 2011, 7 (9), 3515-3522.

(58) Tao, H.; Hwang, S.-W.; Marelli, B.; An, B.; Moreau, J. E.; Yang, M.; Brenckle, M. A.; Kim, S.; Kaplan, D. L.; Rogers, J. A.; Omenetto, F. G. Silk-Based Resorbable Electronic Devices for Remotely Controlled Therapy and in Vivo Infection Abatement. Proc. Natl. Acad. Sci. U. S. A. 2014, 111 (49), 17385-17389.

(59) Zamora, R.; Jackson, A.; Seligson, D. Correct Techniques for the Use of Bioabsorbable Implants in Orthopaedic Trauma. Curr. Orthop. Pract. 2016, 27 (4), 469-473.

(60) Kang, S.-K.; Hwang, S.-W.; Yu, S.; Seo, J.-H.; Corbin, E. A.; Shin, J.; Wie, D. S.; Bashir, R.; Ma, Z.; Rogers, J. A. Biodegradable Thin Metal Foils and Spin-On Glass Materials for Transient Electronics. Adv. Funct. Mater. 2015, 25 (12), 1789-1797.

(61) Kang, S.-K.; Hwang, S.-W.; Cheng, H.; Yu, S.; Kim, B. H.; Kim, J.-H.; Huang, Y.; Rogers, J. A. Dissolution Behaviors and Applications of Silicon Oxides and Nitrides in Transient Electronics. Adv. Funct. Mater. 2014, 24 (28), 4427-4434.

(62) Shin, J.; Yan, Y.; Bai, W.; Xue, Y.; Gamble, P.; Tian, L.; Kandela, I.; Haney, C. R.; Spees, W.; Lee, Y.; Choi, M.; Ko, J.; Ryu, H.; Chang, J.-K.; Pezhouh, M.; Kang, S.-K.; Won, S. M.; Yu, K. J.; Zhao, J.; Lee, Y. K.; MacEwan, M. R.; Song, S.-K.; Huang, Y.; Ray, W. Z.; Rogers, J. A. Bioresorbable Pressure Sensors Protected with Thermally Grown Silicon Dioxide for the Monitoring of Chronic Diseases and Healing Processes. Nat. Biomed. Eng. 2019, 3 (1), 3746.

(63) Hwang, S.-W.; Kim, D.-H.; Tao, H.; Kim, T.; Kim, S.; Yu, K. J.; Panilaitis, B.; Jeong, J.-W.; Song, J.-K.; Omenetto, F. G.; Rogers, J. A. Materials and Fabrication Processes for Transient and Bioresorbable High-Performance Electronics. Adv. Funct. Mater. 2013, 23 (33), 4087-4093.

(64) Alonso, J. C.; Ortiz, A.; Falcony, C. Low Temperature $\mathrm{SiO}_{2}$ Films Deposited by Plasma Enhanced Techniques. Vacuum 1992, 43 (8), 843-847.

(65) Hoivik, N. D.; Elam, J. W.; Linderman, R. J.; Bright, V. M.; George, S. M.; Lee, Y. C. Atomic Layer Deposited Protective Coatings for Micro-Electromechanical Systems. Sens. Actuators, A 2003, 103 (1), 100-108.

(66) Lahtinen, K.; Maydannik, P.; Johansson, P.; Käärïinen, T.; Cameron, D. C.; Kuusipalo, J. Utilisation of Continuous Atomic Layer Deposition Process for Barrier Enhancement of Extrusion-Coated Paper. Surf. Coat. Technol. 2011, 205 (15), 3916-3922.

(67) Kääriäinen, T. O.; Maydannik, P.; Cameron, D. C.; Lahtinen, K.; Johansson, P.; Kuusipalo, J. Atomic Layer Deposition on Polymer Based Flexible Packaging Materials: Growth Characteristics and Diffusion Barrier Properties. Thin Solid Films 2011, 519 (10), 31463154.

(68) Lahtinen, K.; Johansson, P.; Kääriäinen, T.; Cameron, D. C. Adhesion of Extrusion-Coated Polymer Sealing Layers to a FiberBased Packaging Material with an Atomic Layer Deposited Aluminum Oxide Surface Coating. Polym. Eng. Sci. 2012, 52 (9), 1985-1990.

(69) Abdulagatov, A. I.; Yan, Y.; Cooper, J. R.; Zhang, Y.; Gibbs, Z. M.; Cavanagh, A. S.; Yang, R. G.; Lee, Y. C.; George, S. M. Al2O3 and $\mathrm{TiO}_{2}$ Atomic Layer Deposition on Copper for Water Corrosion Resistance. ACS Appl. Mater. Interfaces 2011, 3 (12), 4593-4601.

(70) Song, M.-K.; Namgung, S. D.; Sung, T.; Cho, A.-J.; Lee, J.; Ju, M.; Nam, K. T.; Lee, Y.-S.; Kwon, J.-Y. Physically Transient FieldEffect Transistors Based on Black Phosphorus. ACS Appl. Mater. Interfaces 2018, 10 (49), 42630-42636.

(71) Won, S. M.; Koo, J.; Crawford, K. E.; Mickle, A. D.; Xue, Y.; Min, S.; Mcllvried, L. A.; Yan, Y.; Kim, S. B.; Lee, S. M.; Kim, B. H.; Jang, H.; MacEwan, M. R.; Huang, Y.; Gereau, R. W., IV; Rogers, J. A.
Natural Wax for Transient Electronics. Adv. Funct. Mater. 2018, 28 (32), 1801819.

(72) Yang, Q.; Lee, S.; Xue, Y.; Yan, Y.; Liu, T.-L.; Kang, S.-K.; Lee, Y. J.; Lee, S. H.; Seo, M.-H.; Lu, D.; Koo, J.; MacEwan, M. R.; Yin, R. T.; Ray, W. Z.; Huang, Y.; Rogers, J. A. Materials, Mechanics Designs, and Bioresorbable Multisensor Platforms for Pressure Monitoring in the Intracranial Space. Adv. Funct. Mater. 2020, 30, 1910718.

(73) Xie, F.; Deng, X.; Kratzer, D.; Cheng, K. C. K.; Friedmann, C.; Qi, S.; Solorio, L.; Lahann, J. Backbone-Degradable Polymers Prepared by Chemical Vapor Deposition. Angew. Chem., Int. Ed. 2017, 56 (1), 203-207.

(74) Middleton, J. C.; Tipton, A. J. Synthetic Biodegradable Polymers as Orthopedic Devices. Biomaterials 2000, 21 (23), 2335-2346.

(75) Salpavaara, T.; Ellä, V.; Kellomäki, M.; Lekkala, J. Biodegradable Passive Resonance Sensor: Fabrication and Initial Testing. In BIODEVICES 2015 - 8th International Conference on Biomedical Electronics and Devices; SCITEPRESS: 2015; pp 127-131.

(76) Massera, J.; Fagerlund, S.; Hupa, L.; Hupa, M. Crystallization Mechanism of the Bioactive Glasses, $45 \mathrm{~S} 5$ and S53P4. J. Am. Ceram. Soc. 2012, 95 (2), 607-613.

(77) Salpavaara, T. Inductively Coupled Passive Resonance Sensors: Readout Methods and Applications; Tampere University of Technology: 2018. 